Wright State University

CORE Scholar

Psychology Faculty Publications

Psychology

2-1998

\title{
Victory by Design: War, Information, and Cognitive Systems Engineering
}

John M. Flach

Wright State University - Main Campus, john.flach@wright.edu

Gilbert G. Kuperman

Follow this and additional works at: https://corescholar.libraries.wright.edu/psychology

Part of the Psychology Commons

\section{Repository Citation}

Flach, J. M., \& Kuperman, G. G. (1998). Victory by Design: War, Information, and Cognitive Systems Engineering. .

https://corescholar.libraries.wright.edu/psychology/397

This Report is brought to you for free and open access by the Psychology at CORE Scholar. It has been accepted for inclusion in Psychology Faculty Publications by an authorized administrator of CORE Scholar. For more information, please contact library-corescholar@wright.edu. 


\section{NOTICES}

When US Government drawings, specifications, or other data are used for any purpose other than a definitely related Government procurement operation, the Government thereby incurs no responsibility nor any obligation whatsoever, and the fact that the Government may have formulated, furnished, or in any way supplied the said drawings, specifications, or other data, is not to be regarded by implication or otherwise, as in any manner licensing the holder or any other person or corporation, or conveying any rights or permission to manufacture, use, or sell any patented invention that may in any way be related thereto.

Please do not request copies of this report from the Air Force Research Laboratory. Additional copies may be purchased from:

$$
\begin{aligned}
& \text { National Technical Information Service } \\
& 5285 \text { Port Royal Road } \\
& \text { Springfield, Virginia } 22161
\end{aligned}
$$

Federal Government agencies registered with the Defense Technical Information Center should direct requests for copies of this report to:

Defense Technical Information Center

8725 John J. Kingman Road, Suite 0944

Ft. Belvoir, Virginia 22060-6218

\section{TECHNICAL REVIEW AND APPROVAL}

$$
\text { AFRL-HE-WP-TR-1998-0074 }
$$

This report has been reviewed by the Office of Public Affairs (PA) and is releasable to the National Technical Information Service (NTIS). At NTIS, it will be available to the general public, including foreign nations.

This technical report has been reviewed and is approved for publication.

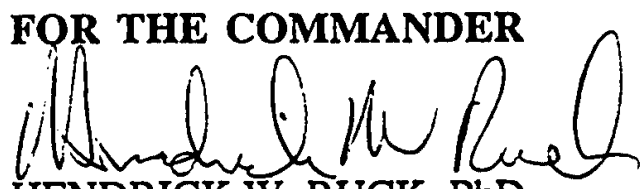

HENDRICK W. RUCK, PhD

Chief, Crew System Interface Division

Air Force Research Laboratory 
Public reporting burden for this collection of information is estimated to average 1 hour per response, including the time for reviewing instructions, searching existing data sources, gathering and maintaining the data needed, and completing and reviewing the collection of information. Send comments regarding this burden estimate or any other aspect of this collection of intormation, including suggestions for redueing this burden, to Washington Headquarters Services, Directorate for information Operations and Reports. 1215 Jefferson

Davis Highway, Suite 1204, Arlington. VA 22202-4302, and to the Office of Management and Budget. Paperwork Reduction Project 10704-0188I. Washington, DC 20503.

\begin{tabular}{l|l|l} 
1. AGENCY USE ONLY (Leave blank) & 2. REPORT DATE & 3. REPORT TYPE AND DATES COVERED
\end{tabular}

4. TITLE AND SUBTITLE

February 1998

Victory by Design: War, Information, and Cognitive Systems Engineering

6. AUTHOR(S)

* John Flach, Gilbert Kuperman

* Wright State University

Dayton, $\mathrm{OH} 45435$
Interim Report. 1 Sep 97 to 28 Feb 98
5. FUNDING NUMBERS

C: F41624-94-D-6000

PE: $62202 \mathrm{~F}$

PR: 7184

TA: 10

WU: 46

8. PERFORMING ORGANIZATION REPORT NUMBER

10. SPONSORING/MONITORING AGENCY REPORT NUMBER

AFRL-HE-WP-TR-1998-0074

$2255 \mathrm{H}$ Street

Wright-Patterson AFB OH 45433-7022

11. SUPPLEMENTARY NOTES

12a. DISTRIBUTION AVAILABILITY STATEMENT

Approved for public release; distribution is unlimited.

\section{ABSTRACT (Maximum 200 words)}

This report discusses the new field of cognitive systems engineering (CSE) and explores the applicability of the CSE paradigm to the domain of information warfare (IW). CSE's goal is the application and design integration of information technology (including both human and automated information processing systems) to facilitate work. CSE defines work as : effort to move through a problem space to achieve specific objectives. Information warfare represents a work domain wher the effective management of information must incorporate the effective utilization of rapid advances in technology (e.g., sensors, communications, and display devices). The report examines IW and Basic Air Force Doctrine within the framewo of Rasmussen's abstraction hierarchy, and uses the abstraction/decomposition matrix as a framework to develop an experimental approach in which to explore how emerging command control, communications, computer, and information (C4I) systems may be used to improve tactical decision making. Decision-cycle time and robustness of decisions are identified as performance predictors. For further inquiry, the report recommends using naturalistic observation and other inductive methods to explore specific phenomena and to direct subsequent hypothesis generation. The report concludes tha. design of future C4I automated systems should include CSE analytical techniques to ensure system flexibility as well as increased efficiency.

\section{SUBJECT TERMS}

Information Warfare (IW), Cognitive Systems Engineering (CSE), Rasmussen's Abrstraction Hierarchy, Decision Making, OODA Loop, Situation Awareness (SA)

15. NUMBER OF PAGES

64

16. PRICE CODE
17. SECURITY CLASSIFICATION OF REPORT

UNCLASSIFIED
18. SECURITY CLASSIFICATION OF THIS PAGE 
This page intentionally left blank. 


\section{PREFACE}

This effort was accomplished under Contract F41624-94-D-6000, Delivery Order 0007 for the Air Force Research Laboratory's Human Effectiveness Directorate, under the direction of the Crew System Interface Division, Information Analysis and Exploitation Branch (AFRL/HECA). It was completed for the prime contractor, Logicon Technical Services, Inc. (LTSI), Dayton Ohio, under Work Unit No. 71841046: "Crew Systems for Information Warfare." Mr. Don Monk was the Contract Monitor.

The authors wish to thank the project manager, Mr. Robert L. Stewart of LTSI, for his ongoing guidance and assistance and Ms. Elisabeth W. Fitzhugh, also of LTSI, for her technical editing services. 


\section{TABLE OF CONTENTS}

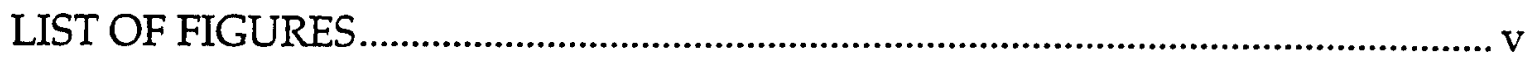

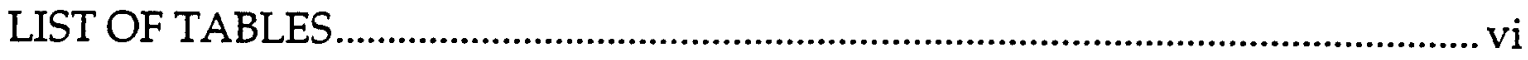

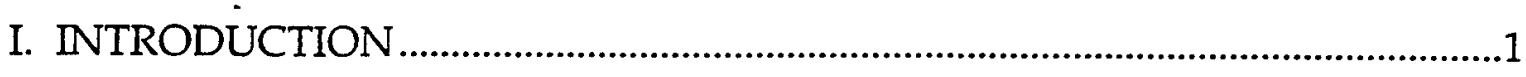

II. COGNITTVE SYSTEMS ENGINEERING: AN HISTORICAL PERSPECTIVE..5

III. THE COGNITIVE SYSTEMS ENGINEERING FRAMEWORK.......................14

IV. INFORMATION WARFARE: A COGNITIVE ENGINEERING

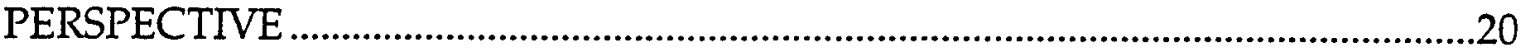

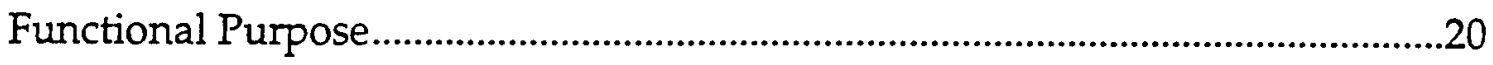

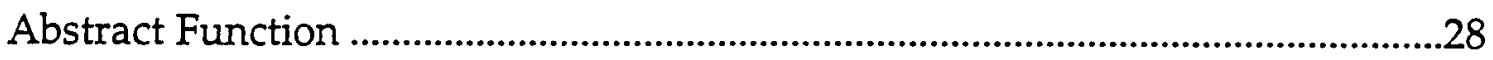

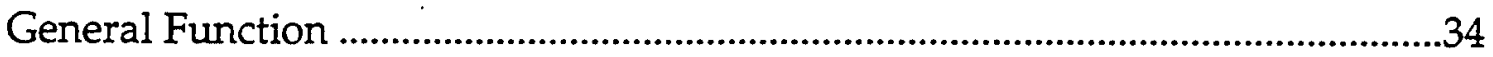

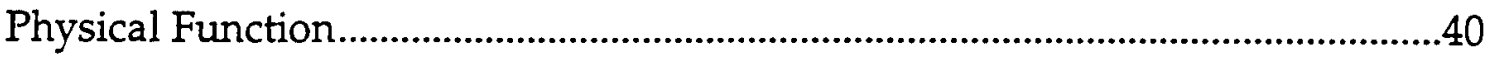

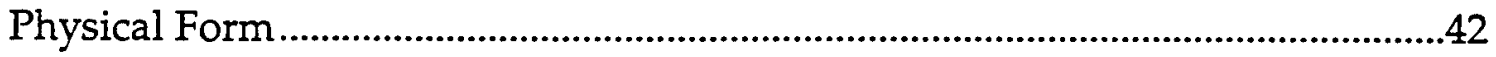

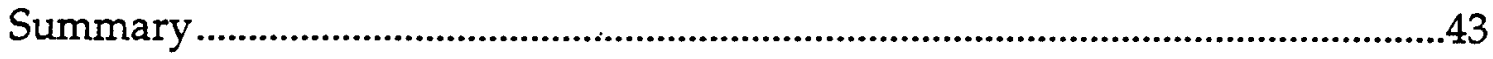

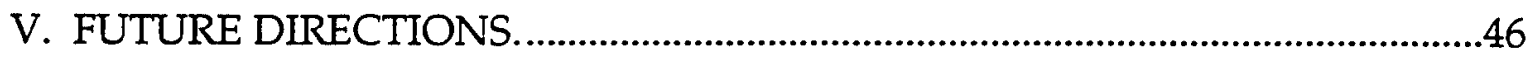

Hypothesis Testing vs. Hypothesis Generation ...................................................46

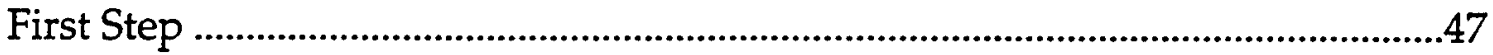

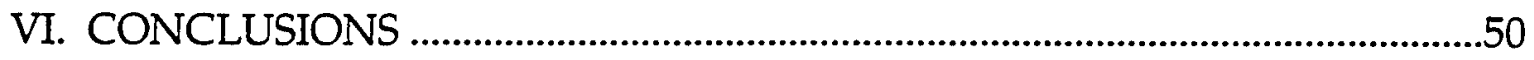

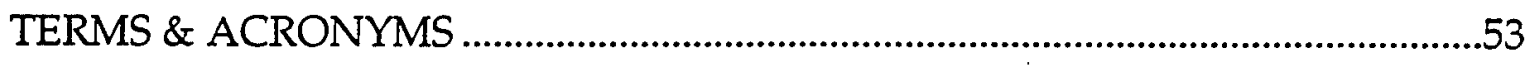

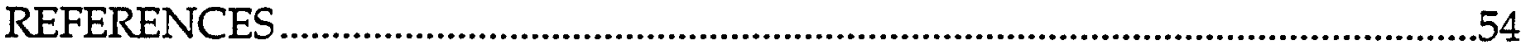




\section{LIST OF FIGURES}

Figure 1: A framework for analyzing situations. A full understanding of a situation requires descriptions at multiple levels of abstraction and at different levels of decomposition.

Figure 2: Rasmussen's (1986) abstraction hierarchy represents a nested hierarchy in which relatively few categories provide a meaningful characterization of the functional purpose of a complex system, but many more categories are needed to meaningfully characterize distinctions in physical form.

Figure 3: An illustration of how different aspects of a cognitive task analysis fit within the overall analysis space defined by the abstraction and decomposition dimensions. Reasoning down the diagonal helps to reveal the rationality that determines why things are done. Reasoning up the diagonal helps to reveal the causal relations that determine how things are done (from Flach, Eggleston, Kuperman, \& Dominguez, 1998)

Figure 4: The principles of war related to three fundamental aspects of IWcommand \& control, counterinformation, and information assurance. .23

Figure 5: A two-dimensional space (decision-cycle speed $x$ robustness/adaptability) for characterizing the performance of intelligent agents.

Figure 6: The OODA Loop: Observe, Orient, Decide, Act..........................................35

Figure 7: Klein's RPD model of naturalistic decision making illustrates the closed-loop coupling of perception and action...........................................................35

Figure 8: The military command structure as a rigid, vertical hierarchy or as a dynamic system of interacting elements (Adapted from Brungess, 1994). .......36

Figure 9: Electromagnetic warfare can be viewed as a nested set of control loops. The outer loops have a longer time constants.

Figure 10: A hypothetical view of the general functional flow for IW (adapted from Homer, 1996).

Figure 11: Explicit representation of problem finding as part of the closed-loop perception-action coupling (from Klein Associates, 1997)...

Figure 12: Fleshing out the CSE framework with some observations about IW..45 


\section{LIST OF TABLES}

Table 1: An historical context for approaches to human-machine systems..........12

Table 2: Scales of degrees of automation ............................................................40

Table 3: Key considerations for function allocation ..............................................41 


\section{INTRODUCTION}

...the highest form of leadership is to thwart the enemy's plans....Therefore the skillful leader subdues the enemy's troops without any fighting. He captures their cities without laying siege to them. He overthrows their kingdom without lengthy operations in the field. With his forces intact he disputes mastery of the empire, and without losing a man, his triumph is complete. The weapon, not being blunted by use, remains sharp and perfect.

This is the method of attacking by stratagem. (p. $19-20$ )

What enables the wise sovereign and good general to strike and conquer, achieving things beyond the reach of ordinary men, is foreknowledge

Sun Tzu (1966 adaptation by Rudnicki)

The principal factor altering the nature of the threat posed by the modern IADS is the treatment of data and information. As a direct descendent of the technology revolution, the introduction of information and data-processing networks has transformed the modern IADS. (p. 163)

JSEAD must evolve beyond the classic "destroy and jam" strategies of resource-rich times when US SEAD technology, personnel training, and firepower outstripped virtually any opponent. In adapting to the IADS's transition from shooter-based to information-based orientations, JSEAD must focus increasingly on information denial as its primary task. The unwitting transition from a shooter-based to an information-based IADS provides modern SEAD strategy with the key vulnerability of the modern IADS structure: paralyze the enemy by denying the ability to acquire, process, or transmit data. (p. 167)

Brungess (1997)

American military officers today most often refer to Clausewitz's unified concept of a general friction (Gesamtbegriff einer allgemeinen Friktion) as the "fog and friction" of war. The diverse difficulties and impediments to the effective use of military force that those possessing military experience instinctively associate with this phrase are generally acknowledged to have played significant roles in most, if not all, of the wars since Clausewitz's time. Even in a conflict as inundated with technically advanced weaponry as the 1991 Persian Gulf War (Operation Desert Storm), there was no shortage of friction at any level, tactical, operational, strategic, or even political. Indeed, close examination of Desert Storm suggests that frictional impediments experienced by the winning side were not appreciably different in scope or magnitude than they were for the Germans during their lightning conquest of France and the Low Countries in May 1940. (p. 1)

Watts (1996)

The proceedings of the board convened by the U.S. Navy to investigate the (Iranian airliner) incident show little sign of any primary role for 'bubble' formation aboard Aegis cruisers (United States Department of Defense, 1988). Instead, the role of the multiple technical systems, which heretofore served primarily to feed information to the tactical operations officer seem to have been reversed. Aboard the Vincennes, the Aegis-directed, computer-operated anti-aircraft missile system is the primary system, with the ship's captain primarily involved in deciding whether to activate its firing mode or not. In this situation, the operator has become an input, not an integrator, and the captain an authorizor rather than a commander of action. Fordism has come to the Navy, one of the last repositories of craft skills and the apprenticeship method in the U.S.

Rochlin (1993) 
The quotations on the preceding page are included as evidence that the art of war has always depended on (and will continue to depend on) the ability to manage information. Some have speculated that advances in surveillance and information technologies will lift the "fog of war" and allow "forces total command of future battlefields" (Admiral Owens, cited in Inside the Navy, 23 January 1995, p. 3. Referenced by Watts, 1996). However, Watts (1996) presents a convincing argument that "the prospects for eliminating friction entirely appear quite dim because friction gives every evidence of being a built-in or structural feature of combat processes" (p.2). Watts (1996) further argues that "the roots of surprise" are found "in circumstances that effect honest, dedicated, and intelligent men. The possibility of such surprise at any time lies in the conditions of human perception and stems from uncertainties so basic that they are not likely to be eliminated, though they might be reduced" (p. 46). Watts' argument is consistent with observations of the impact of information technologies in other fields (e.g., Perrow, 1984). Generalizing from these observations, Klein (1997) concludes that any increase in clarity brought about by advances in information technologies will be counteracted by pressure to "expedite decision cycles." The result will be a "situation where commanders are making faster decisions, at the same level of uncertainty that they were used to" (p. 15). Rochlin (1993), argues further, that friction is a desirable attribute. He argues that friction may be essential to stability in complex organizations because it can "give an organization embarking on an incorrect or errant course the opportunity to review and possibly to recover before major problems occur" (p. 198). Rochlin's analysis emphasizes the fact that friction has both negative and positive attributes. The checks and balances that resist the implementation of a "good" decision may be essential for protecting the system against "bad" decisions. Friction may be an essential attribute for a high reliability organization. Thus, this report starts from the assumption that uncertainty and the requirement to process information to extract meaning have always been and will remain fundamental to the art of war.

Despite the argument that managing information has always been central to the art of war, there is a pervasive feeling (e.g., Whitaker \& Kuperman, 1996) that we are in the midst of a paradigm shift or "revolution in military affairs" (RMA) driven by developments in information technology (including advances in sensors, displays, communications, and computing devices). Brungess's (1994) analysis of developments in Integrated Air Defense Systems (IADS) and the implications for the suppression of enemy air defenses (SEAD) mission provides a good example of how information and communication technologies are changing modern warfare. This feeling of a paradigm shift has generated the construct "information warfare" (IW) and this construct has 
become the banner for focused efforts of the Air Force and other branches of the Department of Defense (DoD) to get out in front of the new technology and its application in warfare. This effort reflects increasing awareness that the masters of the new technologies will be the masters of information and that the masters of information will be the victors in future conflicts (as they have always been in the past).

The challenge to get out in front of advances in communications and information technologies is not unique to the domain of war. This challenge is pervasive in modern society. It is also being faced by the transportation industry, manufacturing, energy production, chemical process control, education, etc. Virtually, every aspect of life is touched in some way by these advances. In response to this challenge, a new discipline is emerging-cognitive systems engineering (CSE). The target phenomenon for this new discipline is the application and design integration of information technology to facilitate work. Work is defined quite broadly to include any focused effort to move through a problem space (i.e., work domain) to achieve specific objectives. Information technology is also defined broadly to include both artificial (e.g., computers) and natural (e.g., human experts) information processing systems.

The development of a new discipline reflects a growing sense that no existing paradigm (e.g., information science, control theory, psychology, industrial engineering, etc.) spans the phenomenon of work; further, the pieces defined by various existing paradigms do not appear to add up to a comprehensive understanding of the phenomenon. Stated simply, the problem of work has emergent properties that can not be completely understood within the current disciplinary frameworks. Extrapolations from these disciplines fail to predict the impact of new technologies (e.g., the paperless office) and fail to provide a foundation for design decisions.

The development of a new discipline also reflects an increasing appreciation of the limits of a reductionist paradigm in science and the assumption of linearity upon which that paradigm is based (e.g., Gleik, 1987; Waldrop, 1992). The problem of work is increasingly being cast within the context of nonlinear dynamics (Flach, 1997). This new appreciation is reflected in a changing value system. In reductionist paradigms, control and internal validity were paramount. In the emerging paradigm, ecological validity takes precedence. Thus, science is moving out of the laboratories to engage problems in their natural ecology. Rather than looking to experimental physics as the model for investigation, scientists in the new discipline are increasingly looking to fields such as ethology and anthropology (e.g., Hutchins, 1995; Klein, Orasanu, Calderwood, \& Zsambok, 1993) for their methods and models. 
This report has two complementary objectives. The first objective is to introduce the new field of CSE to those who are wrestling with the problems of IW. The second objective is to begin exploring the IW problem as an opportunity to test the CSE paradigm. The next section will give a brief introduction to CSE. Then the IW problem will be framed in the context of the emerging paradigm. This will help to introduce the IW problem and will provide a more concrete view of CSE. The final section will lay out a proposal for how the CSE paradigm might be applied to the problem of designing the tools that will lead to victory in the new millennium. 


\section{COGNITIVE SYSTEMS ENGINEERING: AN HISTORICAL PERSPECTIVE}

Many developments in science and engineering have contributed to shaping the field of CSE. Even a dedicated attempt to write the history of the field would be incomplete. However, even an incomplete perspective on some of the historical factors that have shaped the field will help readers to better appreciate why CSE has evolved as a discipline. Therefore, I will begin the section with a brief (and biased) review of what I consider to be some important factors that have shaped CSE.

One important root of CSE was the work of Taylor and Gilbreth on "Scientific Management" (e.g., see Konz, 1987). This work was inspired by the technologies that enabled mass production (as well as by the economic opportunities offered). The key contribution of these men was the importance that they gave to measurement and standardization. First, they helped to establish "time" or "rate" (units/time) as a fundamental ruler for judging the "best way" or "the "right way." Armed with this ruler, they had a basis for controlled comparisons by which the best way to shovel coal or the best way to lay bricks could be empirically determined. Further, these controlled experiments provided a basis for shifting the responsibility for choosing the "work method" from the individual worker or artisan to the manager. It became management's responsibility to provide resources needed to determine the best way and to provide the training and incentives required to get the workers to comply. Also, assembly lines needed to be designed. Because of the number of people involved, the time and money were not available to let assembly lines evolve to a stable configuration. To a large extent, the stability had to be designed into the system (the line needed to be "balanced") if it were to function properly. Thus, the time of component operations needed to be predictable. This led to increasing standardization of methods and tools. Thus, the industrial engineer's or efficiency expert's job was to determine the "best way" through empirical tests on component operations; to organize those components into a balanced configuration to produce safe, efficient, and stable processes; and to implement training and incentive programs so that workers would comply with the standards upon which the design was developed.

In addition to the introduction of empirical methods, an enduring theme that can be traced to Taylor and Gilbreth is that increased effort (working harder) was not the only path to increased productivity. For example, Taylor showed that it was possible to increase productivity by mandating rest breaks. People began to recognize that it was possible to increase productivity by "working smarter." 
Rochlin (1993) presents an interesting discussion of some of the negative side effects of the Scientific Management approach. These side effects arise from the conflict between efficiency (which often depends on limiting friction) and reliability (which often benefits from increased friction in terms of checks and safe guards). Negative side effects from the Scientific Management approach include de-skilling workers and disenfranchising workers from a sense of ownership or responsibility for the quality of the product as a whole.

Whereas, the prime mover for Taylor and Gilbreth was efficiency, World War II (and the technology of war) and, later, the development of nuclear power plants, caused increased concern about issues associated with safety. Efforts to determine the "right way" shifted from an emphasis on "time" to an increased concern about "human error" as a "cause" of potentially catastrophic system failures. The Human Engineering Division within the Air Force's Armstrong Laboratory was an early center for studying human performance in the aviation domain. Fitts and Jones' analyses of pilot error in operating aircraft controls (1947a) and of reading and interpreting aircraft instruments (1947b); and Christensen's (1947) analysis of navigation were early examples of studies of cognition in the wilds of aviation. Fitts and Jones' analyses were based on retrospective verbal reports from pilots. Analyses of the errors reported by pilots inspired laboratory studies of such things as shape coding of controls (Jenkins, 1947) and alternative designs for altimeter displays (Grether, 1949) that eventually led to design innovations. Christensen's (1947) field observations of navigators earned him membership in the Pole Vaulter's Club as the first civilian to fly over the North Pole in an Air Force aircraft. These field observations were followed up with experimental evaluations (1949) that led to the design of improved plotters that became the Air Force standard.

Similar work was being done in Great Britain by researchers such as Bartlett and Craik who studied the effects of stress and fatigue on skilled performance in the "Cambridge cockpit" (designed around a Spitfire cockpit). The Cambridge program made many important "contributions in the areas of aircrew selection and training, the effects of sleep loss and fatigue, and various aspects of visual perception and display design" (Edwards, 1988, p. 7). The combination of field observations with empirical laboratory studies set the flavor for "human engineering" analyses to come. However, the balance between field observations and empirical evaluations achieved in this early work is a standard that is rarely achieved today.

The work of Fitts and Bartlett (and their colleagues) is often recognized as a critical step toward the development of the formal disciplines of human factors (engineering psychology or ergonomics). Many people currently active in the field proudly trace their intellectual roots to either Fitts or Bartlett. Several important themes emerged from this era. First, the work in these laboratories 
further demonstrated the promise of an empirical, experimental program for investigating the "best way." Second, the emphasis on achieving the "best way" shifted from the managers of the work to the designers of the tools (technology). It became clear that the probability of human error was influenced by the design of tools. Finally, the most important theme was that the errors were often traced to failures to process information. There was an increased appreciation for the mental or information processing aspects of work (e.g., perception, memory, and decision making).

Research on human error in nuclear power got great impetus as a result of the accident at Three Mile Island. Early work (e.g., Technique for Human Error Rate Prediction [THERP]) characterized human error in terms of error probabilities and analyzed the work environment in terms of performance shaping factors (PSFs) that could potentially increase or decrease the probability of human error. These PSFs reflected general design principles (e.g., consistency in the layout of instruments) that had their origin in the early "human engineering" analyses of Fitts and his colleagues.

However, because of the high degrees of automation in nuclear power production, attention began to shift from the perception-/action-based errors (slips) that dominated Fitts and Jones's analyses, to errors of intention (mistakes). In the automated world of process control, the operator was less a real time controller and more a supervisor-whose principal function was to detect and diagnose faults. In this domain, much of the interesting "activity" was below the surface. Thus, it was difficult to make inferences about the factors that influenced performance from observing activities alone. Also, it was difficult to characterize the problem solving processes in terms of probabilities. Verbal protocol analysis became a critical supplement to field observations, and qualitative models of the strategies of the human problem solver began to replace the more quantitative chronometric and probability-based analyses.

RIS $\varnothing$ National Laboratory was an important center for early research on human fault diagnosis (Vicente gives a brief account of the early years at RIS $\varnothing$; 1997). Rasmussen and Jensen's (1973; see also Rasmussen, 1986; Rasmussen, Pejtersen, \& Goodstein, 1994) field study of electronic trouble-shooting was an important early study. It relied extensively on verbal protocols. These studies were conducted in the electronics shop at RIS $\varnothing$. Audio recordings were made of technicians as they diagnosed problems with scientific instruments that were brought to them to repair (e.g., multichannel analyzers, oscilloscopes, TV receivers, etc.). The technicians were not asked to introspect about their thought processes, but were asked to "merely tell what they were trying to accomplish, what they were doing and/or observing, and with which instruments" (Rasmussen et al., 1994, p. 86). Analysis of the protocols allowed multiple strategies for diagnosis to be identified and described. An important aspect of 
this work was that the strategies most commonly adopted by the technicians (e.g., topographic search) were not the ones that were predicted by abstract analysis of problem solving (e.g., hypothesis and test). Rasmussen (1986) considers whether the strategies of the technicians were rational:

The experiment discussed here clearly indicates that the task is defined by the technicians primarily as a search to find where the fault originates in the system. They are faced with a system which they suppose has been working properly, and they are searching for the location of the discrepancy between normal and defective states. They do not see the task as a more general problem-solving task in order to understand the actual functioning of the failed system and thus to explain why the system has the observed faulty response... What is rational depends upon the performance criteria adopted by the person. Normally a reasonable criterion for a maintenance technician is to locate the fault as quickly as possible, and only in special circumstances will his criterion be that of minimizing the number of measurements.... From this point of view, the procedures found in our records are rational since in most cases the faults were found within very reasonable times.... The system designer with his theoretical background may quite naturally value as rational the "elegant" deductive procedure which is informationally very efficient and based upon few observations, but this criterion is not the appropriate one on the basis of which performances in real life maintenance work can be judged.

(p. 55-56)

Despite the productivity and influence of the work at RIS $\varnothing$, much of the work on human factors and human machine systems tended to emulate the experimental methods and laboratory paradigms derived from the work of Fitts and the Applied Psychology Unit at Cambridge. Through the '70s and the ' 80 s there was a heavy emphasis on experimental rigor. Field studies such as the work on electronic trouble shooting at RIS $\varnothing$ were exceptions, rather than the rule. Most of the work on human performance and cognition utilized abstract experimental paradigms (e.g., sine wave tracking, probe reaction time tasks, probability judgments, visual search, syllogisms, etc.). These paradigms were assumed to reflect general, fundamental aspects of human performance and there was relatively little concern about representativeness. Naturalistic field studies were rarely reported in the technical literature. Chronometric analyses dominated the literature and verbal protocol analyses were generally regarded with deep skepticism.

Attention and workload became a central theme for laboratory-based empirical work in the '70s and ' 80 s. The problem of Three Mile Island and, increasingly, problems in aviation and other domains were viewed as problems of "too much data." Measuring "mental workload" became a critical challenge for researchers. Important design questions focused on: How many people were 
needed to meet the data processing demands of a job (e.g., is a single-operator attack helicopter feasible)? How can automation be used to off-load processing demands from the human operator (e.g., can the copilot be replaced by an automated pilots associate)? How can the data be packaged (integrated in graphical displays or distributed over modalities) to minimize the workload?

In the mid ' 80 s, in part stimulated by a failure to achieve consensus on a reliable ruler for measuring workload, and in part inspired by advances in graphical displays and successes such as the graphical user interface on personal computers, the characterization of the problem began to shift. The problem appeared to be less a limitation in data processing and more a problem of understanding. During this period, it became increasingly clear that the capacity to process information depended critically on the representation of that information. Extracting information from a table of numbers might be overwhelming, extracting that same information from a graph might be virtually effortless. Further, it was not simply the "form" of the representation, but the correspondence between the form and the meaning of the process (work) that was being represented (e.g., Flach \& Bennett, 1996; Rasmussen \& Vicente, 1989; Woods, 1991).

In the aviation domain, this shift in emphasis from data processing to understanding was evident in the emergence of a new construct-situation awareness. Here, the inspiration came from observations of striking differences in how individuals responded to the complex information processing demands that might be associated with combat. One individual is consistently overwhelmed and lost, where another responds instinctively and almost effortlessly. Both individuals have the same external representation. However, one appears to have a superior internal representation-better situation awareness. In other words, one pilot is more expert!

During this period, Klein and his colleagues (e.g., Klein, Calderwood, \& Clinton-Cirocco, 1986) began studying decision making in natural environments. They began by "observing and taking protocols from urban fireground commanders about emergency events that they had recently handled" (Klein, 1993, p. 139). Klein (1993) discovered that:

The fireground commanders' accounts of their decision making do not fit into a decision-tree framework. The fireground commanders argued that they were not "making choices," "considering alternatives," or "assessing probabilities." They saw themselves as acting and reacting on the basis of prior experience; they were generating, monitoring, and modifying plans to meet the needs of the situations. We found no evidence for extensive option generation. Rarely did the fireground commanders contrast even two options. We could see no way in which the concept of optimal choice might be applied. 
Moreover, it appeared that a search for an optimal choice could stall the fireground commanders long enough to lose control of the operation altogether. The fireground commanders were more interested in finding actions that were workable, timely, and cost effective. (p. 139)

As a result of observations of decision making in natural environments, Klein developed his "recognition-primed decision model" which emphasized the importance of perception and the "zeroing-in" aspects of the decision problem. Equally important, however, was the fact that Klein's work helped to stimulate wider interest in the problem of "expertise" and "naturalistic decision making" (e.g., Klein, Orasanu, Calderwood, \& Zsambok, 1993) and helped to legitimize verbal protocol analysis and field observations as essential to a complete understanding of human performance in complex work environments.

In 1995, Hutchins' book "Cognition in the Wild" was published. This book summarized a comprehensive field (ethnograghic) study of ship navigation that began in the "80s. Hutchins (1995) chose the title "in the wild" to distinguish between "the laboratory, where cognition is studied in captivity, and the everyday world, where human cognition adapts to its natural surroundings. I hope to evoke with this metaphor a sense of an ecology of thinking in which human cognition interacts with an environment rich in organizing resources" (p. xiv). Hutchins' description of how variations in map design shaped the computation problem, making some problems easier and others harder, provides a clear demonstration of the fundamental link between the "right way" and the "right representation."

The realization that the functionality of a representation (internal or external) relates to its correspondence to problem semantics (to a situation) has opened up the problem of work analysis. Whereas, the emphasis of the information processing approach was on internal human processing constraints (channel capacity, bottlenecks, or resource limitations), there is now increasing interest in constraints within the situation. There is growing appreciation that the search for the "right way" has to be framed in terms of both an analysis of human information processing (awareness) and an analysis of the semantics intrinsic to the work domain (situation). In other words, the problem of the "right way" involves a distributed information processing system that spans the human and the work ecology. This is the focus of CSE-to understand the semantics of situations and to discover how awareness can be facilitated through the engineering of representations. These representations can be engineered through training (internal representations) or through the design of visualization tools (external representations).

The works of Rasmussen, Klein and Hutchins also help to show that it was possible for researchers to discover general principles and broad insights 
into human cognition by delving deeply into the particulars of specific work domains. These works illustrate that the image of human cognition that was molded from general, laboratory paradigms did not always hold up in the wild. The behavior of technicians, fireground commanders, and navigators often did not conform to expectations based on logical analyses. Further, the "nonsense" laboratory tasks derived from the logical analyses of information processing tended to miss the essence of the natural tasks. Semantic and contextual aspects that were critical to performance in the natural world tended to be abstracted out of the laboratory tasks.

In sum, the safety tradition was inspired by field observations of natural phenomena (e.g., accidents). However, early researchers (Fitts' human engineering group and Bartlett's applied psychology unit) were extremely innovative in extracting key features of the natural phenomenon that could be studied in the laboratory, using rigorous controls and quantitative measures of performance. The success of the laboratory paradigms tended to overshadow the phenomenon-based insights that inspired them. As a result, the '70s and ' $80 \mathrm{~s}$ were dominated by a paradigmatic information processing approach to human performance where the laboratory paradigms became the phenomena of interest. Field studies were rare, and it was generally assumed that natural tasks could be understood as a combination of the laboratory tasks (e.g., landing an airplane might be considered to be a combination of tracking, visual search, and decision making tasks).

However, pockets of phenomena-centered research were maintained. Rasmussen, Klein, and Hutchins are prominent representatives of researchers who were not seduced by the power of laboratory paradigms. These researchers maintained a phenomenon-centered science. In part, this was motivated by the practical need to address problems in natural systems like nuclear power plants. But it was far more than this. It was also motivated by a sense that human cognition in the wild was fundamentally different than cognition observed in captivity; a sense that the context-free, logical puzzles and toy worlds of the cognition laboratory were not representative of the demands faced in natural work domains; and a sense that performance in the laboratory, where human limitations were easily catalogued and the fallibility of human reasoning seemed obvious, was not representative of the creative, adaptive nature of people in their fields of expertise. Rasmussen, Klein, and Hutchins were not alone. However, their work was prominent and helped draw attention to earlier insights of people such as deGroot (e.g., Vicente \& Wang, 1998), Brunswik (Hammond, 1993; Kirlik, 1995), and Gibson (Flach, Hancock, Caird, and Vicente, 1995). Gradually, there seems to be growing appreciation for the importance of ethnographic observations for a basic understanding of cognition. Researchers are beginning to consider ways to scale the methods of observation and analysis to the complexity of the natural phenomenon, as opposed to cutting the phenomenon 
into pieces that fit conveniently into laboratory paradigms. This is the challenge that has stimulated the new discipline of CSE-to understand the holistic and emergent properties of work in a way that will generalize to design-to achieve expertise by design.

This section has presented CSE in an historical context. Table 1 summarizes this discussion in terms of four "eras" of work on human-machine systems. These eras are not necessarily distinct historical epochs, but represent themes that, though interleaved in time, are distinctive in terms of the technological changes that are addressed. Each era has framed the problem differently and each era has focused on a different metric for comparing and evaluating potential solutions.

Table 1: An historical context for approaches to human-machine systems

\begin{tabular}{|c|c|c|c|}
\hline ERA & Key Technologies & Defining Problem & Measurement \\
\hline $\begin{array}{c}\text { Scientific } \\
\text { Management }\end{array}$ & $\begin{array}{c}\text { Assembly Line } \\
\text { Mass Production }\end{array}$ & $\begin{array}{c}\text { Efficiency } \\
\text { Standardization } \\
\text { Line Balancing }\end{array}$ & $\begin{array}{c}\text { Rate } \\
\text { Pieces/Minute }\end{array}$ \\
\hline Human Error & $\begin{array}{c}\text { Advanced Military Systems } \\
\text { Nuclear Power }\end{array}$ & $\begin{array}{c}\text { Reliability } \\
\text { Too many human } \\
\text { errors" } \\
\text { Design Guidelines }\end{array}$ & $\begin{array}{c}\text { Error Rate } \\
\text { BHEP } \\
\text { (basic human } \text { rror } \\
\text { probability) }\end{array}$ \\
\hline Overload & $\begin{array}{c}\text { Nuclear Power } \\
\text { Civil Aviation }\end{array}$ & $\begin{array}{c}\text { Attention } \\
\text { (bottlenecks, limited } \\
\text { resources) } \\
\text { "Too much data" }\end{array}$ & $\begin{array}{c}\text { (subjective, physiological, } \\
\text { primary E secondary } \\
\text { task) }\end{array}$ \\
\hline Visualization & Graphical Interfaces & $\begin{array}{c}\text { Situation Atvareness } \\
\text { "Too little } \\
\text { understanding" } \\
\text { Representations }\end{array}$ & $\begin{array}{c}\text { Decision-Cycle Tinte? } \\
\text { Robustness? }\end{array}$ \\
\hline
\end{tabular}

In the first era, the motivating technology was the assembly line. The key problems were efficiency, standardization of methods, and line balancing. The primary performance metric was production rate-how many units per minute could be produced. With the advances in technology arising during World War II and, later, with the development of nuclear power, focus shifted from efficiency to safety or reliability. The defining issue was human error and 
how to reduce the probability of system failure. The primary performance metric was error probability. However, as nuclear process research continued and as other systems (like civil aviation) became more complex, the focus began to shift to the explosion of data that operators were being asked to deal with. Increasingly, system failures were being attributed to limitations of human information processing. The defining issue became attention, and numerous metrics (subjective, physiological, primary task, and secondary tasks) for measuring mental workload were developed. This is still a major concern in human factors. As graphical displays became available, it began to be evident that, with the appropriate representation, large amounts of data could be processed very efficiently. Thus, the focus is now shifting to the problem of understanding or situation awareness-how to integrate complex data in a way that will facilitate understanding. This is the era of data visualization. In the following sections we will suggest two possible metrics for the visualization problem-decision-cycle time and robustness (or adaptability).

The next section will present the CSE framework. A unique feature of the CSE framework is the explicit attempt to analyze situations at multiple levels of abstraction to reveal the constraints that are intrinsic to a work domain. Section IV will begin to flesh out the framework in the context of IW. Hopefully, this exercise will provide insights about both CSE and IW. The final section will present recommendations for a research program to explore IW using the CSE framework. 


\section{THE COGNITIVE SYSTEMS ENGINEERING FRAMEWORK}

Science and technology have always tried to answer the question "how?" How does this or that mechanism work? What are the laws and causal properties that underlie this phenomenon and, in the case of technologies, how can such knowledge be used to develop a useful tool or machine? However, science and technology rarely, if ever, address the question "Why?" It seems to be outside their respective universe of discourse. The question is ruled inadmissible or inappropriate for the methods and capabilities at hand. I reject this absolutely. I submit that questions of how and why are so mutually dependent that they should never be considered independently, and I attribute much of our present circumstance to this unfortunate and unhappy division. Those who know how must always ask why. Those who ask why must always think how. (Hancock, 1996, p. 461)

One of the first considerations for an analysis framework is to specify the "unit" of analysis. That is, what are the "objects" of analysis? Gilbreth introduced the "therblig" as a fundamental unit for motion analysis. Any manual operation could be characterized in terms of these fundamental units of motion. The information processing approach introduced stages of information processing to characterize qualitatively different mental processes. These stages represented fundamental cognitive operations, and tasks were described in terms of the relative demands on these stages (e.g., perceptual tasks, memory load, decision tasks, and manual tasks). Early work on human error characterized elemental actions (both mental and manual) in terms of basic human error probabilities (BHEPs). An assumption of all these approaches was that there was an elemental level of behavior that could be used to characterize all human interactions. The assumption was that a description of work in terms of its basic behavioral elements would allow inferences about the nature of system performance (e.g., workload, error probability, or response speed). Further, it has been assumed that studies of the fundamental units, stripped of all extraneous context, could provide a human performance database that would support extrapolations to the performance of human-machine systems. In fact, it has generally been assumed that getting rid of the extraneous context was a necessary condition in order to achieve broad generality of inference.

The CSE approach takes a different tack. This approach begins with the assumption that context is not extraneous, but fundamental in shaping human performance. Thus, it is important that analyses address the situation level constraints. In fact, one could go further and argue that because of the adaptive nature of human cognition, the situation constraints will generally dominate for experienced or expert operators performing in the domains of their expertise. 
The context-free laboratory research provides important information about the lower thresholds of performance and may generalize well in predicting the performance of novices (or experts in unfamiliar contexts). However, it is very difficult to extrapolate from these context-free tasks to predict the performance limits of experts in their natural work ecology. The literature is full of examples (such as the observations from Rasmussen and Klein cited in the last section) where generalizations from the laboratory have proven to be very naive when tested against the performance of experts in their natural work environments.

When one shifts the focus from the human information processor to the situation, one quickly discovers that there is no single atomistic level of description that is privileged (e.g., see Marr, 1980; Rasmussen, 1986; Rasmussen et al., 1994). As Marr and Rasmussen have both noted, the multiple levels of analysis are loosely coupled. There must be a mapping from one level to another, but there are also emergent properties at each level. That is, a description at one level of abstraction will provide insights into the phenomenon that are not possible at other levels. A complete understanding requires that the analyses address multiple levels of abstraction.

Rasmussen (1986) has characterized the multiple levels of description in terms of two dimensions-level of abstraction and level of decomposition. This framework is shown in Figure 1. Rasmussen (1986) has distinguished five different levels for characterizing complex socio-technical systems with respect to the abstraction dimension. Brief descriptions are presented here. However, these levels will be fleshed out more fully in the context of IW in later sections of this report:

Functional Purpose. This level identifies the goals and values of the work domain. What is the purpose of the system and what are the figures of merit for gauging the success of the system?

Abstract Function. This level specifies the problem domain in terms of abstract dimensions that bridge between the values reflected at the level of functional purpose and the physical constraints that bound the flow of activities and the operation of technologies to support those goals.

General Function. This level decomposes the system into processing units with identifiable inputs and outputs. Each processing unit is characterized in terms of a transfer function that translates inputs to outputs.

Physical Function. This level identifies the types of technology (e.g., human operator, computer, hydraulic or mechanical system, etc.) which is associated with each of the functions. 
Physical Form. This level provides a detailed accounting of the space/time properties of the system (e.g., where things are located, what's connected to what, etc.) and of system performance (e.g., what happens, when).

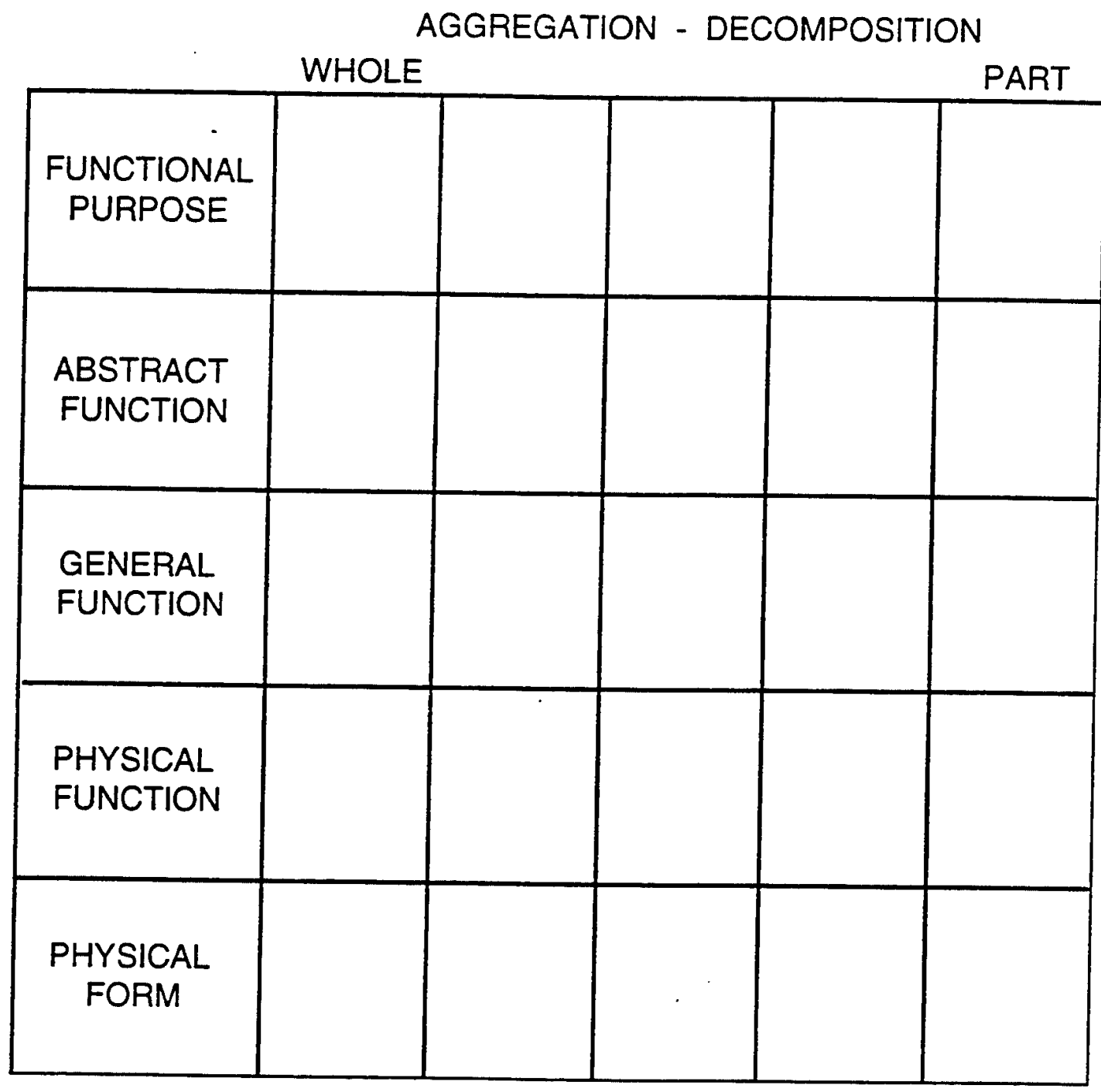

Figure 1: A framework for analyzing situations. A full understanding of a situation requires descriptions at multiple levels of abstraction and at different levels of decomposition.

Each level of abstraction refers to qualitatively different categories of constraints that contribute to the situation. These qualitatively different categories are related in a nested hierarchical structure. Categories at higher levels within this hierarchy provide the rational context for understanding why lower level constraints are significant. Categories at lower levels in the hierarchy provide the physical details of how constraints at higher levels can be 
implemented. The nested hierarchy is typically represented as a triangle (Figure 2). This graphic reflects the intuition that relatively few categories are needed to meaningfully characterize high level constraint of the work domain. However, for lower levels many more categories and distinctions are relevant to a meaningful characterization. This difference in level of decomposition reflects the second dimension of analysis-part-whole decomposition. Together these dimensions create the two-dimensional space for characterizing the analysis process shown in Figure 1. As a result of inquiry into many different work domains and.after analyzing many verbal protocols of domain experts, Rasmussen found that experts tend to reason along the diagonal of this space. That is, expert reasoning tends to move from global descriptions of functional goals to detailed specifications of particular actions on specific components.

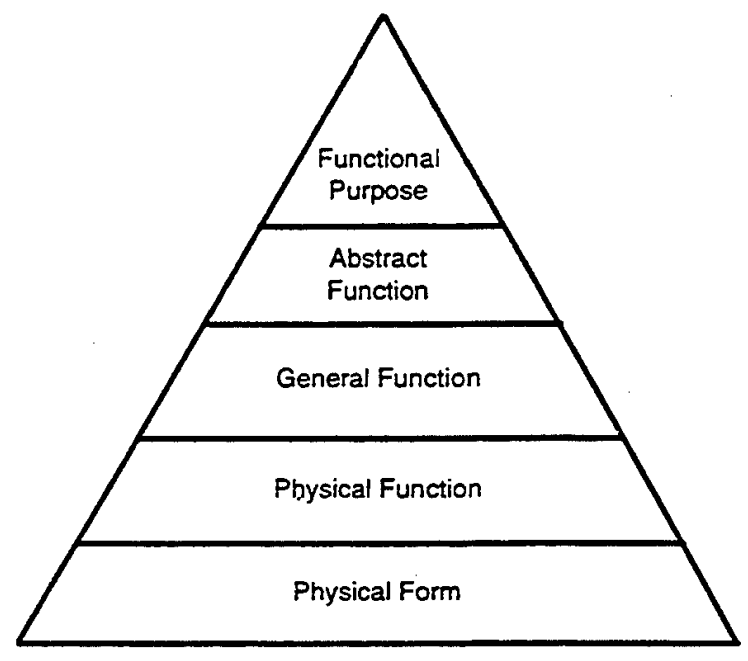

Figure 2: Rasmussen's (1986) abstraction hierarchy represents a nested hierarchy in which relatively few categories provide a meaningful characterization of the functional purpose of a complex system, but many more categories are needed to meaningfully characterize distinctions in physical form.

Figure 3 (from Flach, Eggleston, Kuperman, \& Dominguez, 1998) shows how different types of classical system analyses fit within the abstraction/decomposition space for understanding the problem. Note that these different analyses fall along the diagonal of the analysis space and thus are consistent with the pattern seen in expert reasoning. The hope is that by integrating information represented along this diagonal we can begin to address questions of both how and why.

A unique attribute of the CSE approach is an attempt to integrate across the component analyses to achieve a global understanding of the distributed control system. Top down relations along the diagonal help to uncover the 
underlying rationality of the work domain. This rationality provides the reasons why things are done or the reasons why things are significant. This is important to understanding the focusing-in problem of cognition. That is, what causes certain features to pop out in a way that allows experts to focus in on critical aspects of a problem early in the analysis. In other words, what is the basis for the high situation awareness achieved by experts? How is it that they can recognize good solutions as the first to be considered (e.g., see Klein, 1993)? Further, how can representations be designed to facilitate these recognitional processes and to support high levels of situation awareness?

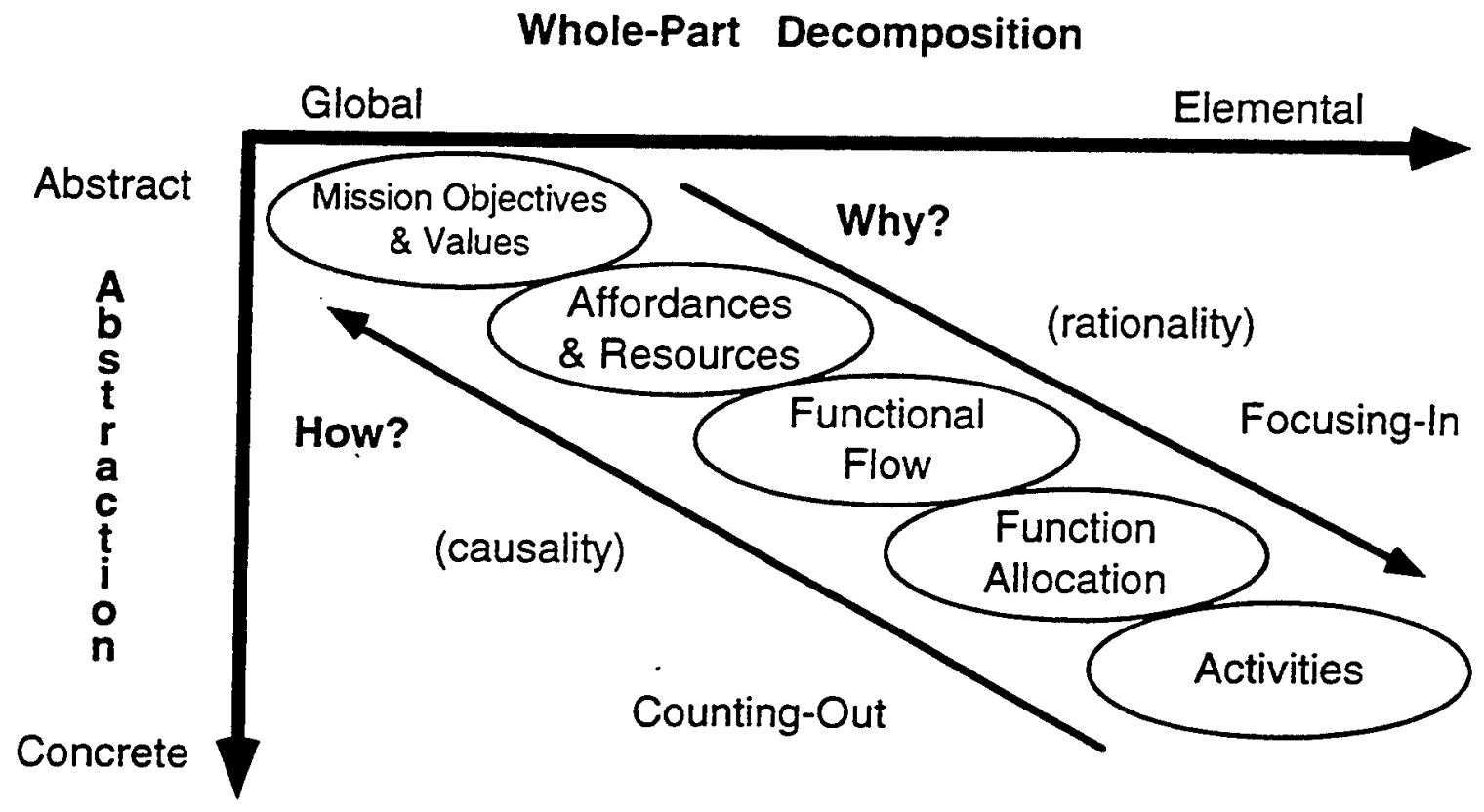

Figure 3: An illustration of how different aspects of a cognitive task analysis fit within the overall analysis space defined by the abstraction and decomposition dimensions. Reasoning down the diagonal helps to reveal the rationality that determines why things are done. Reasoning up the diagonal helps to reveal the causal relations that determine how things are done (from Flach, Eggleston, Kuperman, \& Dominguez, 1998)

Bottom up relations along the diagonal help to uncover the causal structure within the work domain. This causal structure provides a productionlike description of how things can be accomplished within the work domain. This kind of description is critical for the design of rule-based, counting-out processes that are typical of classical artificial intelligence and expert systems. These relations can be critical in the design of automated systems: Automating the well-behaved (rule-based or routine) aspects of the work can free up human resources to be focused on supervising the "messier" aspects of the work. 
Within the CSE approach the top down and bottom up relations are complementary perspectives that contribute to a complete understanding of the workspace. A primary goal of the CSE approach is to make the links along this diagonal explicit (as opposed to an implicit understanding encapsulated within a particular analyst's experience). Unlike classical and modern (e.g., optimal) approaches to control systems that begin with restrictive assumptions (e.g., linearity, a quadratic cost function, etc.) in order to build quantitatively powerful models of the system, CSE focuses on the assumptions, themselves. Classical and optimal control models make assumptions that turn messy problems into well-defined problems that allow quantitative solutions. But CSE is all about the "messiness," because that is why operators are included in most control systems-to deal with the messiness (the unanticipated variability). If the problems were well-defined and met the limiting assumptions of classical or modern control models, then there would be no need for the human. The goal of cognitive engineering is to understand the messiness as the most interesting part of the problem. As a result, the models of CSE tend to rely more on the qualitative insights of control theory, rather than on the quantitative methods. This does not mean that quantitative models are not used or that they are not valuable tools for developing qualitative insights. But the quantitative models are not sufficient. In many respects, CSE is most important for exploring regions just outside the limits of a quantitative control analysis of the problem. These are the regions where automated solutions are likely to break down. These are the regions where human expertise is an essential ingredient for success. In this respect, CSE is a means of providing a qualitative glimpse over the horizon set by limits of our quantitative control models. It is for this reason that the CSE approach is particularly well-suited for addressing the messy problems of "fog and friction" that are at the heart of IW.

From a design perspective, CSE generally focuses on the nature of problem representations as a means for dealing with messy problems. Through the design of interfaces, CSE attempts to build external representations that allow operators to directly perceive significant features of a problem (e.g., see Bennett, Nagy, \& Flach, 1997; Flach \& Bennett, 1996; Rasmussen \& Vicente, 1989; Vicente, 1992; Woods, 1991). Through the design of training systems and protocols, CSE helps to attune internal representations (in Rasmussen's [1986] terms, the dynamic internal model) to significant features of the problem (e.g., Flach, Lintern, \& Larish, 1990; Flach, 1997). It is too early in the analysis process to speculate about the details of interfaces or training programs for IW. However, the final section of this report will speculate on the directions that research and analysis might take that will eventually provide a basis for advancing our ability to manage the friction and fog of war in the context of current and future advances in information technologies. 


\section{INFORMATION WARFARE: A COGNITIVE ENGINEERING PERSPECTIVE}

This section will be organized around the different levels of abstraction. At each level different aspects of the IW problem will be discussed.

Fundamental questions at each level will concern the availability of descriptions at the appropriate level of decomposition.

\section{Functional Purpose}

The fundamental issue at this level of abstraction is, why does the system exist? What is the purpose? The first place to look for answers to these questions is within the definition of IW. One definition of IW is "any action to deny, exploit, corrupt, or destroy the enemy's information and its functions; protecting ourselves against those actions; and exploiting our own military information functions" (Widnall \& Fogleman, 1995, pp. 3-4; cited in Whitaker \& Kuperman, 1996). This definition explains what IW is in terms of actions (deny, exploit, etc.) and the object of those actions (information). However, the definition does not address the issue of purpose. What are the functions of information? Why is control of information desirable?

The answers to the questions above cannot be found by focusing on the technology (the means of IW). Rather, focus must be shifted to the use of this technology. What is the information used for? The purpose is to achieve victory in war. Thus, the first step in a CSE analysis is to ask what the information technology is used for. So, in this section, the emphasis will be on the ends of war.

The means of war may change, but at the highest level, the goals and purposes of war have not changed much since the time of Sun Tzu. At a global level, the availability of information technologies will not change the ultimate purposes of war. Basic aerospace doctrine (Department of the Air Force, 1992) outlines nine principles of war:

Objective: Direct military operations toward a defined and attainable objective that contributes to strategic, operational, or tactical aims.

Offensive: Act rather than react and dictate the time, place, purpose, scope, intensity, and pace of operations. The initiative must be seized, retained, and fully exploited.

Mass: Concentrate combat power at the decisive time and place.

Economy of Force: Create usable mass by using minimum combat power on secondary objectives. Make the fullest use of all forces available. 
Maneuver: Place the enemy in a position of disadvantage through the flexible application of combat power.

Unity of Command: Ensure unity of effort for every objective under one responsible commander.

Security: Protect friendly forces and their operations from enemy actions that could provide the enemy with unexpected advantage.

Surprise: Strike the enemy at a time or place or in a manner for which he is unprepared.

Simplicity: Avoid unnecessary complexity in preparing, planning, and conducting military operations. (Department of the Air Force, 1992, Fig 11, p. 1)

Figure 4 shows one possible network of interactions among these nine principles that might reflect some of the trade-offs involved in IW. This hierarchical structure does not represent differences in priority. Rather, the hierarchy highlights functional interdependencies among the nine principles. These interdependencies may be critical for evaluating trade-offs across competing goals within IW.

At the top of this hierarchy is Unity of Command. One of the fundamental problems with advances in information technology is the distributed nature of information and the requirement to coordinate multiple distributed actors. The challenge is to maintain a unified command while supporting distributed execution; the key is for the distributed elements to function as a coordinated whole, acting toward an appropriate goal. In Owens' (1995) terms the challenge is to get "the right information to the right warfighter at the right time." Whitaker and Kuperman (1996) compare the problems of IW to problems of computer-supported cooperative work (CSCW) and group decision support systems (GDSS) in general. These challenges have created a need for a shared information space- "... a medium that could be used dynamically ... to help people to share their view of the world with others through joint manipulation of each person's personal models of the situation" (Bannon, 1989, p. 13). Rochlin, LaPorte, and Roberts' (1987) contrasted the formal command structure on an aircraft carrier with the more informal command structure that evolved (self-organized) to deal with the distributed information and the dynamic demands during landing on an aircraft carrier. This command structure appears to adapt to changing information and changing loads. Whitaker and Kuperman (1996) suggest the construct, "Common Battlespace Picture," to characterize a central representation that is mutually accessible, mutually interpretable, mutually meaningful, and mutually manipulable. The communication structures on aircraft carriers (as described by Rochlin et al., 1987) seem to have evolved naturally so that a Common 
Battlespace Picture emerges from the interactions among the crew. The challenge of IW will be to provide the information links to facilitate the development of such a shared representation among joint forces over a much broader battle campaign. Rochlin (1993) uses the naval term "having the bubble":

When you have the bubble, all of the charts, the radar displays, the information from the console operators, and the inputs from others and from the senior staff fall into place as parts of a large coherent picture. Given the large amount of information, and the critical nature of the task, keeping the bubble is a considerable strain. On many U.S. Navy ships, operations officer shifts are held to no more than two hours. 'Losing the bubble' is a serious and ever-present threat; it has become incorporated into the general conversation of operators as representing a state of incomprehension or misunderstanding, even in an ambiance of good information.

This notional 'bubble' is one of the key elements in obtaining high and reliable systemic performance in organizational settings that involve considerable risk, large and basically uncontrollable uncertainties, and a high degree of organizational as well as technical complexity, operating in real time situations where decisions with irrevocable consequences must be made quickly, in real time, on the spot (Rochlin, 1989). At the cognitive level, the conception of the 'bubble' makes it possible for Navy operations officers, air traffic controllers, and (in a somewhat different context) experienced pilots to integrate a system of vast operational, technical and cognitive complexity into a single, mental representative spatio-temporal map that organizes and orders the flow of information and allows decisions to be made on the basis of overall, systemic situations and requirements. (p. 215)

On one hand, information technology, including computer networks and the use of the electromagnetic spectrum for sensing and communications, has led to an explosion of the amount of information available and has contributed to the dispersion of that information. On the other hand, information technology offers important opportunities for integrating that information to create a unified framework for making command decisions. Thus, depending on how it is used, information technology can exacerbate the problems or it can provide unique solutions to the Unity of Command challenge.

It is also important to note that, as Rochlin et al.'s (1987) analysis of the aircraft carrier suggests, Unity of Command does not necessarily mean centralized command. Watts (1996) points to economics as an example of a selforganizing system. He quotes Hayek (1988), who writes that "modern economics explains how such an extended order can come into being, and how. it, itself, constitutes an information-gathering process, able to call up, and to put to use, widely dispersed information that no central planning agency, let alone 
any individual, could know as a whole, possess, or control" (p. 14). This is one of the major challenges of IW-to design command and control structures that maximize the effectiveness of information technologies to achieve coordinated and effective action.

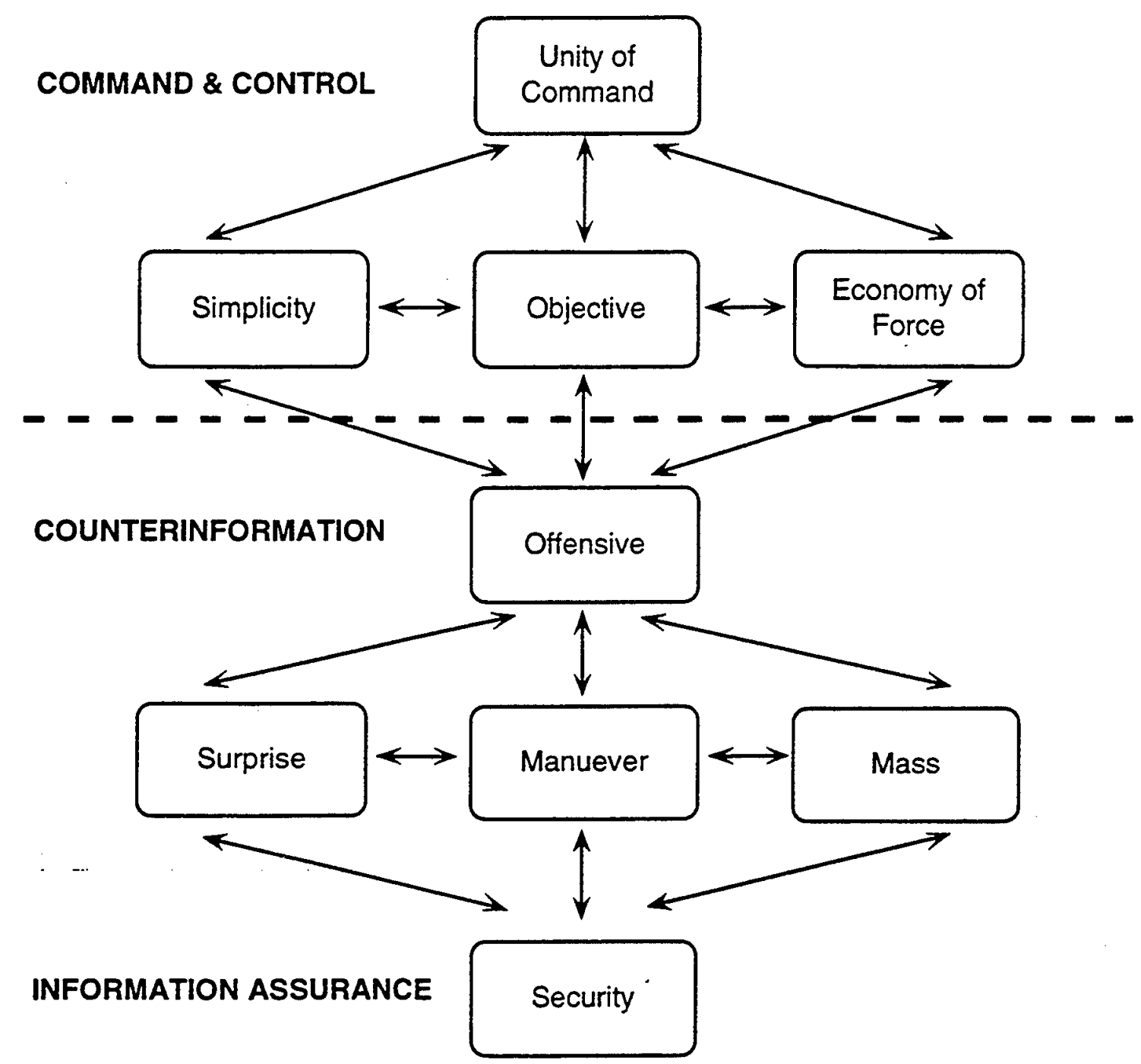

Figure 4: The principles of war related to three fundamental aspects of IW-command \& control, counterinformation, and information assurance.

In order to achieve Unity of Command in the face of the complexities of advanced distributed information systems, it will be increasingly.important to cut through the fog and friction of war to focus on the crux of the problem. That is, Simplicity will be at a premium. Klein's (1997) group has found that in Marine field headquarters and in nuclear power plant control rooms there were many more people than necessary. These excess people added to the complexity 
of the problem unnecessarily. They were a source of noise and increased computational load. It was difficult to identify the key decision makers so that they could be provided the "right information" at the "right time." In both cases, efficiency and effectiveness of operations were increased by eliminating people from the control rooms. The lesson here is that more data does not necessarily require more data handlers. Added agents can also add to the information burden, without facilitating the decision process. Sometimes, less is more.

Hand in hand with Simplicity is the need for clearly defined Objectives. More than anything else, it was a failure to maintain clearly defined objectives that hindered operations in Vietnam. Clearly defined objectives will be very important, so that distributed cooperating agents don't end up working at crosspurposes. These objectives (or shared intentions) will help provide a context in which it will be easier to interpret and anticipate local adaptations among cooperating agents. To a large extent, the meaning of an act can only be judged relative to the intentions. If the intentions are vague and ill-defined, then the meaning of actions will be ambiguous and coordination will be difficult to achieve. Clearly defined objectives help to focus attention and resources on the crux of the problem.

Economy of Force has become an increasingly important concern since the end of the Cold War and the break-up of the Soviet Union. It is becoming increasingly difficult to justify military expenditures, and the joint forces are being challenged to do more with less. Information technologies offer at least three obvious paths to increased economy. First, automation can reduce the number of humans required to operate some systems. Crew sizes have been reduced on aircraft and on ships as a result of advances in automation. Second, automation can reduce the exposure of humans to hazardous situations (e.g., Uninhabited Aerial Vehicles [UAVs] and other remotely controlled vehicles). This can significantly reduce costs associated with attrition. A third source of economy expected from the increased application of information technology is the ability to adapt through software, rather than hardware. That is, in the past, special missions have required specially engineered systems (e.g., the "Wild Weasel" for attacking SAMs [surface-to-air-missiles]). However, with the addition of "smart" systems, a single platform may be able to adapt to a wider variety of applications. Thus, for example, a few aircraft platforms may be adapted to a wide range of missions through software modifications. This translates into economies of scale for production and also significantly reduces maintenance costs.

Simple, clearly defined, affordable Objectives provide the basis for a unified command and control structure that is capable of proactively dictating the time, place, purpose, scope, intensity, and pace of operations. This Offensive posture contributes to (and derives from) our ability to Surprise the enemy, to 
Maneuver effectively, to Mass our resources to attack critical nodes, and to protect the Security of our own resources. Brungess (1997) has contrasted the approach to SEAD during Vietnam and the Gulf War. In Vietnam we were in a reactive mode. We were constantly one step behind developments of the Vietnamese IADS. However, in Desert Storm, superior intelligence, careful analysis, and advanced planning allowed us to set the agenda. We understood the Iraqi IADS better than they did. As a result, we were able to mass our resources to attack critical nodes in the IADS. This enabled the allied forces to gain air superiority very early in the conflict. It is important to realize that the Iraqi IADS system was technologically far superior to what was faced in Vietnam. The Iraqi IADS system was one of the most technologically advanced systems in the world. Our success was not a result of vastly superior technologies. Rather, the Offensive posture was achieved as a result of a superior understanding of how to use the technologies.

Surprise has always been fundamental to the "art of war." In his work by that name, Sun Tzu writes:

All warfare is based on deception. Hence when able to attack, we must seem unable. When using our force, we must seem inactive. When we are near, we must make the enemy believe we are far away. When far away, we must make him believe we are near. Hold out baits to entice the enemy. Feign disorder, and crush him.... Attack him where he is unprepared; appear where you are not expected. (1966, p. 12)

Advances in sensor and information technologies have enormous implications for Surprise. One obvious example is the advances in sensor technologies that have opened up the electromagnetic spectrum to our (and our enemies') vision. Thus, the visual horizon and darkness are no longer sufficient cover to hide our movements and intentions from the enemy. Further, the need to communicate our intentions to widely distributed forces using the electromagnetic spectrum and information/communication networks makes these intentions vulnerable to interception by our enemy. A fundamental challenge of IW will be to balance the need to communicate simple, well-defined objectives to our allies and, at the same time, to shield those intentions from the enemy.

Despite the changes in the information space within which the games of deception will be played, Surprise will continue to hinge on fundamental conditions of human perception (see Watts, 1996). Ultimately, we are dealing with human beliefs and expectations. The nature of the data will change, but the crux of the problem will remain the same-to gain advantage by biasing the beliefs and expectations of the enemy. Surprise is fundamentally an issue of human cognition. 
The art of war requires an ability to maneuver the enemy into positions of disadvantage. Traditionally, this position has referred to a physical place with reference to geographical features. For example, Sun Tzu writes that "we are not fit to lead an army on the march unless we are familiar with the face of the country-its mountains and forests, its pitfalls and precipices, its marshes and swamps" (1966, p. 41). In IW, the terrain will not be defined exclusively in geographical terms. It is important to consider where the mountains, precipices, and swamps are in the information space. What aspects of the information terrain facilitate movement and provide advantages? What aspects of the information terrain retard movement and waste resources? Klein's (1997) analysis of expertise and, in particular, of the barriers to expertise might be a first step to characterizing the information terrain. Klein describes six barriers to expertise: excessive data, pre-processed data, excessive procedures, performing formal analyses, passive data handling (limited ability for information seeking), and interfaces that obscure the big picture. In many respects, these barriers are natural features of the information technology landscape that can only be avoided by careful planning and smart maneuvering.

A key to victory in any engagement is the ability to Mass or concentrate application of power at the decisive place and time. For IW, the decisive place and time may have less to do with enemy manpower or firepower and more to do with the structure of information networks. Information deniability may be decisive. In attacking an IADS, eliminating command and control nodes or information links may do far more damage than eliminating radars or SAMs. Brungess (1994) makes a strong argument that SEAD of the future must define the critical nodes with respect to the distributed information system within the IADS. He writes:

The hallmark of the emerging new age seems to be the growth of informationits management and distribution-as a determinant of power. As a direct consequence of the age of computers, information itself may be the key to power in the twenty-first century. The nation that can control data, deny it to others, or willfully shape it will be preeminent in the wars of the future. In this context, SEAD criteria may be couched more in terms of information denial and shaping than in the more traditional concepts of radar destruction and jamming. (p. 91; emphasis added)

The last principle to consider is Security. Information is a resource that needs to be protected and defended. For many people this is the first issue that comes to mind relative to the construct of IW. Thus, a major component of IW is information assurance, which the Air Force defines as "measures to enhance and protect friendly information and functions" (Department of the Air Force, 1996, p. 6). Security was also a primary consideration of Sun Tzu who wrote: 
The good fighters of old first put themselves beyond the possibility of defeat, and then waited for an opportunity of defeating the enemy.

To secure ourselves against defeat lies in our own hands, but the opportunity of defeating the enemy is provided by the enemy himself. Thus the good fighter is able to secure himself against defeat, but cannot make certain of defeating the enemy. (1966, p. 24)

Consistent with Sun Tzu's intuitions, Security is the foundation for all the other functions. That is, if we cannot ensure the integrity of our information resources-if we can't trust the data or the analyses (information processes)then everything crumbles. The command and control structure falls apart if you cannot trust the command communications or if the simple, well-defined Objectives of the commanders are corrupted by noise in the communication channels. If you can't trust the intelligence data or the projections of your analyses, then you cannot adopt an Offensive posture and you are doomed to be one step behind an opponent with reliable information sources. The planning horizon will be set by the integrity of the information on which it is based.

Thus, Figure 4 organizes the nine principles of war in a way that reflects three fundamental dimensions of IW. At the top is the command and control function. Our ability to define and communicate clear and feasible objectives will increasingly depend on our facility with information management tools. At the intermediate level are issues associated with counterinformation. This involves the real time control of information flow. The key is to stay one step ahead of the enemy - to dictate the time and place of engagements; to maneuver the enemy into positions of disadvantage; and to focus our power where its impact will be most decisive. At the lowest level, the issue is information assurance. Can we protect our information sources from the enemy? Ensuring the integrity of information sources is critical to all aspects of IW.

The top down flow in Figure 4 does not reflect importance. The principles should be viewed as links in a chain. Every link must bear its appropriate load if the chain is to function. However, there is a sense in which the top down flow helps to reveal the coupling across the principles. The top of the diagram tends to reflect strategic constraints. There is increasing demand to approach warfare in an integrated, as opposed to piecemeal, fashion. Brungess (1994) makes the argument in the context of SEAD:

The integrated approach represents the evolutionary trend. Continued piecemeal applications, no matter how desirable they may be, must be viewed in the reality of the evolutionary trend.... Objectives need to be defined as a function of the integrated use of concepts and SEAD weapons, not only 
because doing this makes sense, but because it represents the most appropriate adaptation to changing realities. (p. 82-83)

War can no longer be planned piecemeal around land, sea, and air (or around particular component threats). The services must function as a coordinated and complementary whole. This is why Unity of Command is at the top of Figure 4. Strategies must be formulated to coordinate across forces. These strategies will have to generate clearly defined Objectives that are feasible (relatively Simple and realistic, given the economic constraints).

The bottom up flow in Figure 4 emphasizes the tactical constraints. That is, secure information (Security) will be the basis for tactical decisions that will allow us to hide our intentions from the enemy (Surprise), to determine the time and place for action (Maneuver), and to focus these actions where they will have the largest impact (Mass). These are the foundations for proactively (Offensive) achieving the strategic goals.

Viewed from the same perspective but with somewhat different semantic labels, we must first gain control of the information realm. Given that foundation, we can then proceed to exploit this "high ground" through a wide variety of offensive and defensive information operations. These capabilities and actions will, in turn, serve to enhance our actions across virtually the entire spectrum of the conflict.

\section{Abstract Function}

The fundamental issue at the Abstract Function level is the issue of measurement. In some sense, this level addresses the "currency exchange problem" between the ends at the Functional Purpose level and the means defined at lower levels within the abstraction hierarchy. The problem is to formulate or identify an abstract set of dimensions (measurements) that will allow means to be scored or measured with respect to the desirable goals or values of the system. Without a common reference, it would be impossible to compare and evaluate alternative means. It would be impossible to predict whether a solution was feasible or desirable in comparison to other candidate solutions. The goal at this level of analysis is to generate a low-dimensional description that will facilitate the classification of solutions with respect to their feasibility and with respect to their relative costs and benefits.

Another way to think about the problem of Abstract Function in military terms is to consider the link between strategy and doctrine (discussed at the level of Functional Purpose) and operational art and tactics. "Strategy and doctrine are conceptual; operational art and tactics are pragmatic" (Brungess, 1994; p. 136). Strategy and doctrine set the goals and norms (prescriptions); tactics 
represents the means. The problem at the Abstract Function level is to identify dimensions for measuring tactics that allow these tactics to be compared and evaluated relative to strategic objectives. If this can be done, then these measures will be useful in the design process. They will provide a basis for predicting the "best way."

How do you evaluate systems relative to the goals for IW? Brungess (1994) articulates the measurement problem in the context of SEAD:

SEAD effectiveness in Vietnam was measured by counting destroyed $S A M$ sites and radars. Applying that criteria to the SEAD technologies used in Desert Storm yields a confused, possibly irrelevant picture. SEAD weapons and tactics evolution has outpaced the development of criteria to measure SEAD's total contribution to combat. (p. 51-52)

Brungess (1994) contrasts four approaches to measurement-historical, engineering, commonsense, and object-based. With the historical approach the past becomes the measure of the future-that is, successes in the past are projected into the future. You use what worked in the past. Also, "lessons learned" from past failures might inform design for the future. In stable times, it may be safe to generalize from the past to the future; however, in a time of revolutionary technological breakthroughs, the past may not be representative of the future. The engineering approach focuses on quantitative measures (e.g., probability of kills, probability of survival). However, in order to get stable and comparable numbers, the engineering approach tends to depend on a narrow range of objective tests. These tests typically are chosen to meet the constraints of measurement, and are often based on naive assumptions about the operational context. The commonsense approach to measurement is a reaction to the failures of the engineering approach. Decision makers have grown suspicious of the quantitative models used by the engineering approach. The commonsense approach emphasizes simplicity and consensus. The opinion and recognition of the decision makers become the criteria for measuring the "goodness" of a design. The assumption is that decision makers can recognize a good solution when they see it. Thus, subjective pilot (or, more generally, operator) opinion may be the principal measure of effectiveness.

The fourth approach to measurement, which Brungess (1994) advocates as the preferred approach, is the objective approach. For Brungess the term "objective" is synonymous with "goal" or "function." This approach requires a shift of focus from the activity of the system (e.g., number of kills) to the constraints of the operational space. That is, the measures should be defined with respect to functional goals. Thus, for example, the criteria for evaluating systems for SEAD must reflect the operational goals. The first questions that must be asked are what are the "objectives" of the SEAD mission and what are 
the constraints to achieving those objectives. One quickly realizes that "bombs on target' no longer carries the certainty of desired system destruction that it once did" (p. 169). Today, the objective for the SEAD mission depends more on information deniability than on destroying SAMs, and this must be reflected in measurement.

For information warfare, then, the question is, how do you measure facility in managing information? The rulers used must reflect both the principles of war and the pragmatic constraints on the activities that might serve these principles. The measures should help to differentiate an effective information processor (e.g., expert) from a less effective information processor (e.g., novice). The measures should also provide insights as to what attributes of the systems make a difference. To a large extent, systems for IW are "expert" systems. Thus, the Abstract Function that must be measured is expertise.

At an abstract level, the problem of IW is fundamentally a problem of expertise. Of the many attributes that differentiate novices and experts, two that might be particularly suited to the measurement problems associated with IW are the speed at which they perform and the robustness of their performance. Experts tend to be much quicker to reach a quality solution. Research in numerous fields of expertise show that experts generate high quality alternatives very early (often as the first option considered) relative to novices. Also, experts tend to be more adaptive (robust); that is, they are more flexible in the face of changing demands. Figure 5 illustrates how measures of speed and flexibility might help to identify qualitatively different information processing systems.

Automatons are fast, but rigid. Automatons achieve speed by taking advantage of local consistencies. However, these local consistencies are bounded. In other words, automatons utilize heuristics or short cuts that will only work in particular contexts. These systems break down if the context changes. Note that automatons will function like experts within a narrow scope. If context is stable, automatons are good solutions to the information processing problem. An autopilot is an example of an automaton. An autopilot can be tuned to optimally fly an aircraft, as long as the assumptions about aircraft dynamics and the environment that were designed into the control algorithms hold. If the dynamics change (for example, due to damage to a flight surface) or the environment changes (for example, wind shear) in ways that the designers did not anticipate, most autopilots will not be able to reliably compensate to the changes. One of the problems with Taylorism was that the focus on efficiency tended to drive systems toward performing like "well-oiled machines" and workers tended to be seen as cogs within the machine. The result has been an efficient system, but a very brittle one that cannot easily adapt to changing environments (e.g., changing markets). 


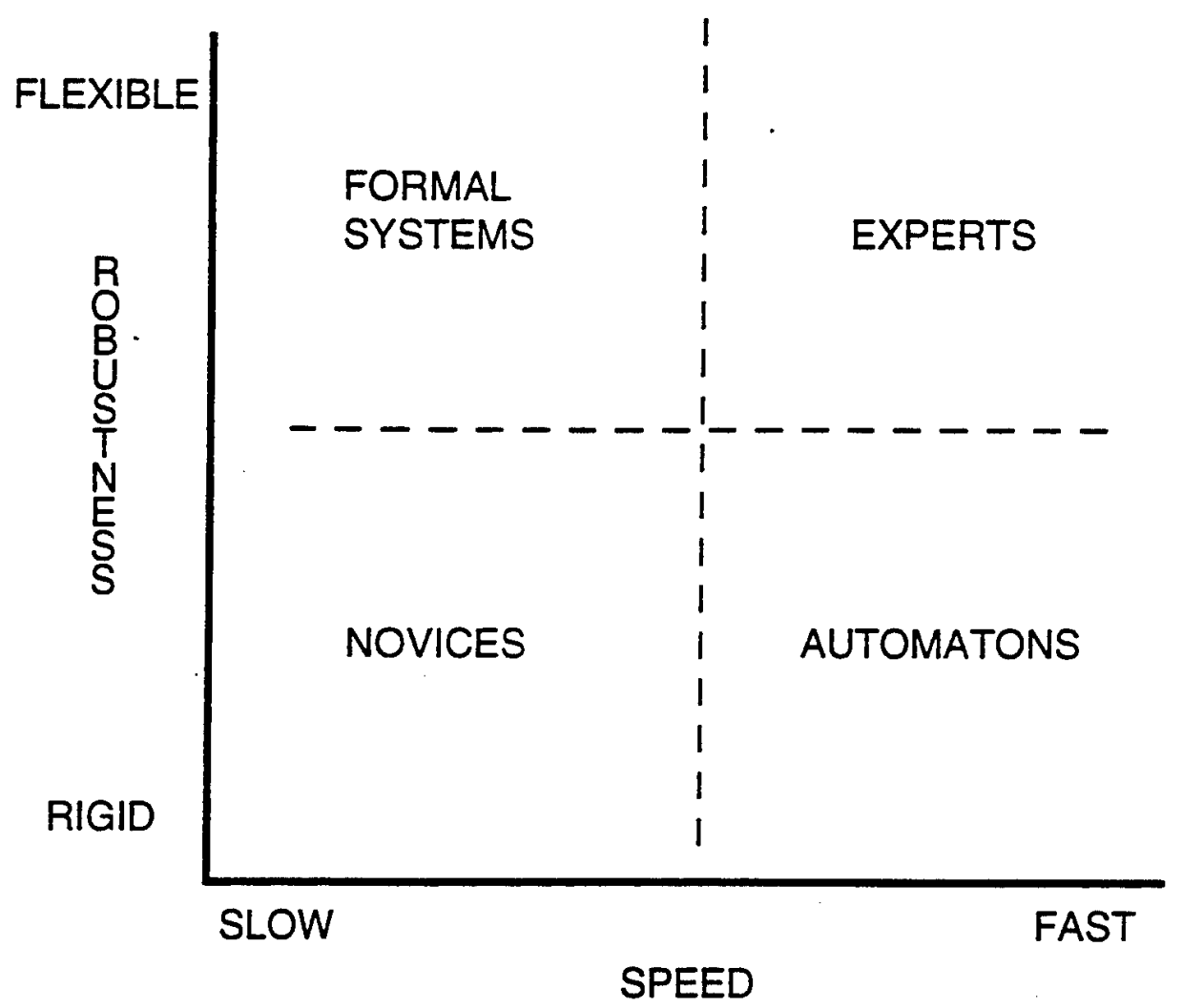

Figure 5: A two-dimensional space (decision-cycle speed $x$ robustness/adaptability) for characterizing the performance of intelligent agents.

Formal systems are extremely flexible. That is, formal systems can be applied across a wide range of situations. However, generality (flexibility) is achieved at the price of high computational load. These systems are not capable of taking advantage of local constraints that might allow short cuts. Formal systems perform like experts when time is unlimited, but these systems break down under time pressure. For example, a formal systems approach to a chess algorithm would involve an exhaustive search of the space of possible moves. Even with great advances in processor speed, the combinatorics of chess set pragmatic time boundaries as to how deep a search is possible (thus bounding the intelligence of the program). Most advanced chess programs are not purely formal systems. The programs incorporate heuristics derived from observations of human experts.

The choice of time and robustness as key dimensions of IW is not simply motivated by intuitions about expertise, but also reflects intuitions about the fundamental nature of war. Watts (1996) chose two metrics for making historical 
comparisons relative to the question of whether the "friction" of war is being reduced as a result of advances in information processing technologies. These dimensions were "decision-cycle times" and "option sets in possibility space." These dimensions seem quite consistent with the framework in Figure 5. The relation between decision-cycle time and speed is obvious. The concept of "option sets in possibility space" may be less obvious, but there is a connection. The option sets in possibility space represents the number of feasible or possible actions (in other words, the degrees of freedom). The number of possible actions can be bounded by the situation. For example, the terrain might constrain the feasible directions for attack or escape. The number of possible actions can also be bounded by internal constraints. Bounded assumptions incorporated in automatons are an example of an internal constraint on action. Thus, the more robust an information processing system, the less its degrees of freedom (options) are constrained. Thus, Watts' (1996) intuitions about the friction of war seem to be consistent with intuitions about expertise. A system will be more expert in dealing with the friction of war to the extent that the system can implement decisions quickly without artificially constraining the possibilities.

If we return to the expertise literature there is an apparent contradiction. Observations of experts (e.g., chess players) show that experts consider many fewer options before choosing an alternative than do novices. One grand master is reported to have responded to the question of how many options he considered before making a move as follows: "Just one, but it's the best one!" This is only an apparent contradiction. This example illustrates the difference between tacit and explicit knowledge. Experts do not explicitly compare and contrast as many alternatives as novices. However, this does not mean that the experts have fewer alternatives. The fact that experts consistently generate the "best" alternative suggests that many options are being considered. It seems that experts are able to zero-in on the correct alternative using tacit perceptual or recognitional processes (e.g., Klein, 1993). The case might be made that it is the efficiency of the tacit perceptual or recognitional processes that allows the expert to be both fast and robust in processing information.

So, speed (or decision-cycle time) and robustness (or the number of options in possibility space) may be two fundamental dimensions that ought to be reflected in performance measures. However, these measures may be too gross for many design and evaluation questions. It might be useful to consider what attributes of information processing systems create the possibility for speed and robustness. Here is where Klein's (1997) analysis of barriers to expertise might help to link the characteristics of expertise to the characteristics of information technologies. In many cases, these technologies are designed to function either as formal systems or automatons. However, developments in graphical displays and visualization technologies (e.g., virtual reality [VR]) may provide an opportunity to enhance perceptual and recognitional processes that 
appear to be fundamental to expertise. In Whitaker and Kuperman's (1996) terms, expertise may depend on the availability of a Common Battlespace Picture that shows the "full space of possibilities" and supports recognitional processes so that the best option within this space can be "seen."

Decision-cycle time and robustness represent the negative and positive aspects of friction. Reducing friction will generally result in faster decision-cycle times, but less robustness. Increasing friction will result in slower, but often more reliable (robust) decisions. The expert is capable of faster decisions, but this does not mean that the expert is always moving forward at the fastest pace. Part of the skill is to "go quick, slowly." For example, novices in sports often rush their actions (and novice readers and speech makers often speak too fast). The key is not how fast you go, the key is to be able to respond at the right time. Sometimes, it is the expert's ability to slow down-to be mindful or heedful of potential dangers or to recognize when to wait for information that is missingthat contributes to increased reliability. The experts can go fast, but they don't have to go fast. They also recognize when it is appropriate to put on the brakes and to wait for more information (let the defense commit before you take your shot). This attribute of expertise is often referred to as "metacognition" (see Dominguez, 1997 for an interesting discussion of the role of metacognition in surgical decision making). This heedful attitude in which decisions are continually monitored, reviewed, and critiqued is a common attribute of highreliability systems. As Rochlin (1993) notes "bubbles cannot be acquired quickly or simply, and they require elaborate and overlapping networks of communications for their establishment and maintenance" (p. 215). Rochlin reports that tactical operations shifts on ships will sometimes overlap by up to an hour to ensure that the "bubble is transferred smoothly to the succeeding tactical officer without a potentially dangerous break in routine or perception" (p. 215).

At a trivial level, all work domains are about expertise. For example, nuclear power plant operation depends on the expertise of the operators and medicine depends on the expertise of doctors and nurses. However, these work domains are not fundamentally about managing information-they're about managing power flow (mass and energy) and about managing health (anatomy and physiology). IW, on the other hand, is fundamentally about managing information. It is about having a clearer, more accurate view of the world than your enemy. It is about shaping your enemy's perceptions and expectations. In Sun Tzu's terms, it is about "defeating your enemy's plans" (1966). If the information war is won, then the need for fighting, destruction, and bloodshed will be minimized. 


\section{General Function}

The next level of abstraction considers IW in terms of the flow of information and action. At this level of analysis, systems are generally described in terms of networks of connected processing stages, where each processing stage can be described either in quantitative terms ( $a$ transfer function) or qualitative terms (process limitations and general properties of inputs and outputs). As.Whitaker and Kuperman (1996) have noted, probably the most cited theoretical construct in the IW literature is the OODA Loop of Boyd (1987). The OODA Loop is a closed-loop organization with the stages Observe, Orient, Decide, and Act, as shown in Figure 6. The OODA Loop emphasizes the dynamic, iterative nature of information processing. The iterative or circular coupling between perception and action have long been overlooked in basic studies of cognition. However, several recent models show an increased appreciation for the iterative nature of cognitive processes. These include Neisser's (1976) perception-action cycle, which is often cited in the literature on situation awareness; Klein's (1993) recognition-primed decision (RPD) model of naturalistic decision making (shown in Figure 7); and Rasmussen's (1986) decision ladder (see also Flach \& Rasmussen, in press).

The cyclic nature of the IW problem has also been reflected in analyses of military missions. Figure 8 (adapted from Brungess, 1994, Figure 17) contrasts the vertical model of information flow that reflects a traditional view of war with the cybernetic model that he feels is a much more accurate characterization of modern warfare.

The cyclic nature of cognition is a critical aspect of the dynamics of information processing and has often been de-emphasized in the basic cognitive research literature that has tended to treat information processing as a linear (horizontal) sequence of independent stages. It has also been de-emphasized in classical models of warfare that treat the flow of information as a linear (vertical) flow of commands and actions. However, it is becoming increasingly clear that any model of $I W$ systems at the functional level will have to address the iterative nature of the process. While the OODA Loop recognizes the circular coupling, it is far too gross (too holistic) to be useful for characterizing the flow of information and action in a way that can inform design decisions. 


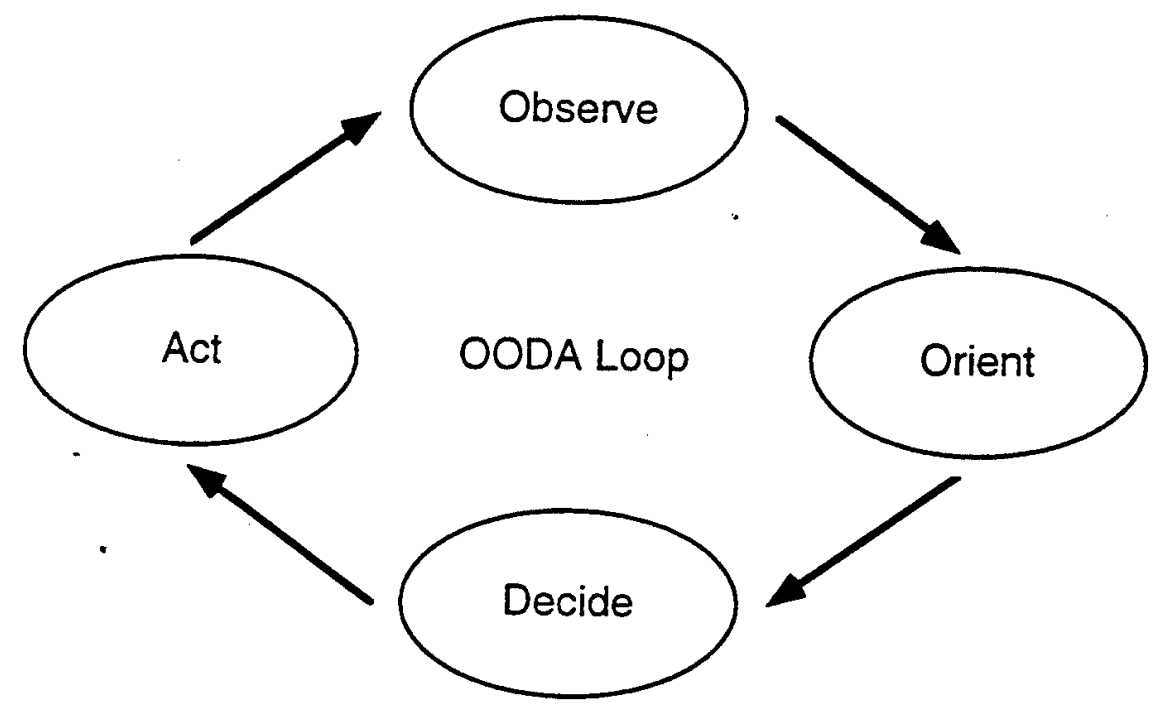

Figure 6: The OODA Loop: Observe, Orient, Decide, Act.

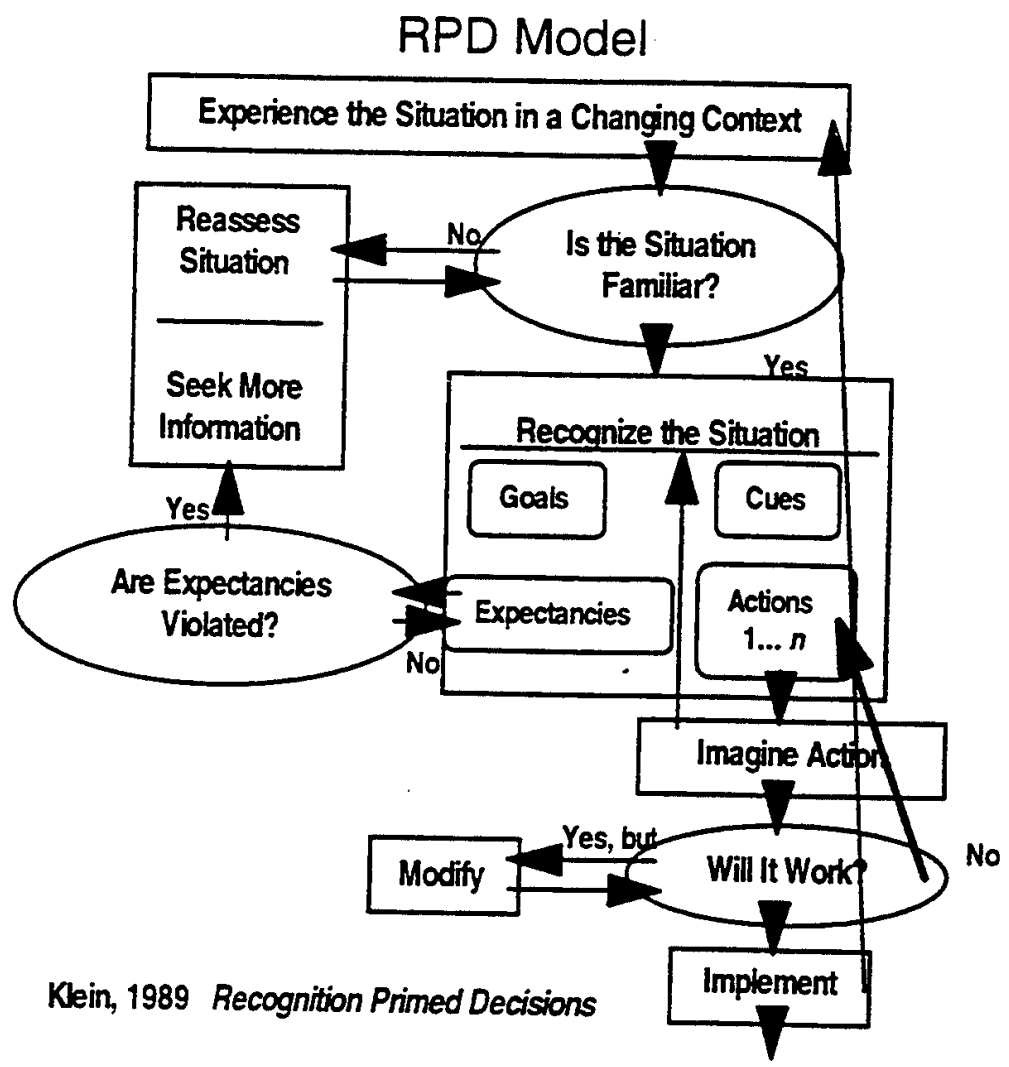

Figure 7: Klein's RPD model of naturalistic decision making illustrates the closed-loop coupling of perception and action: 


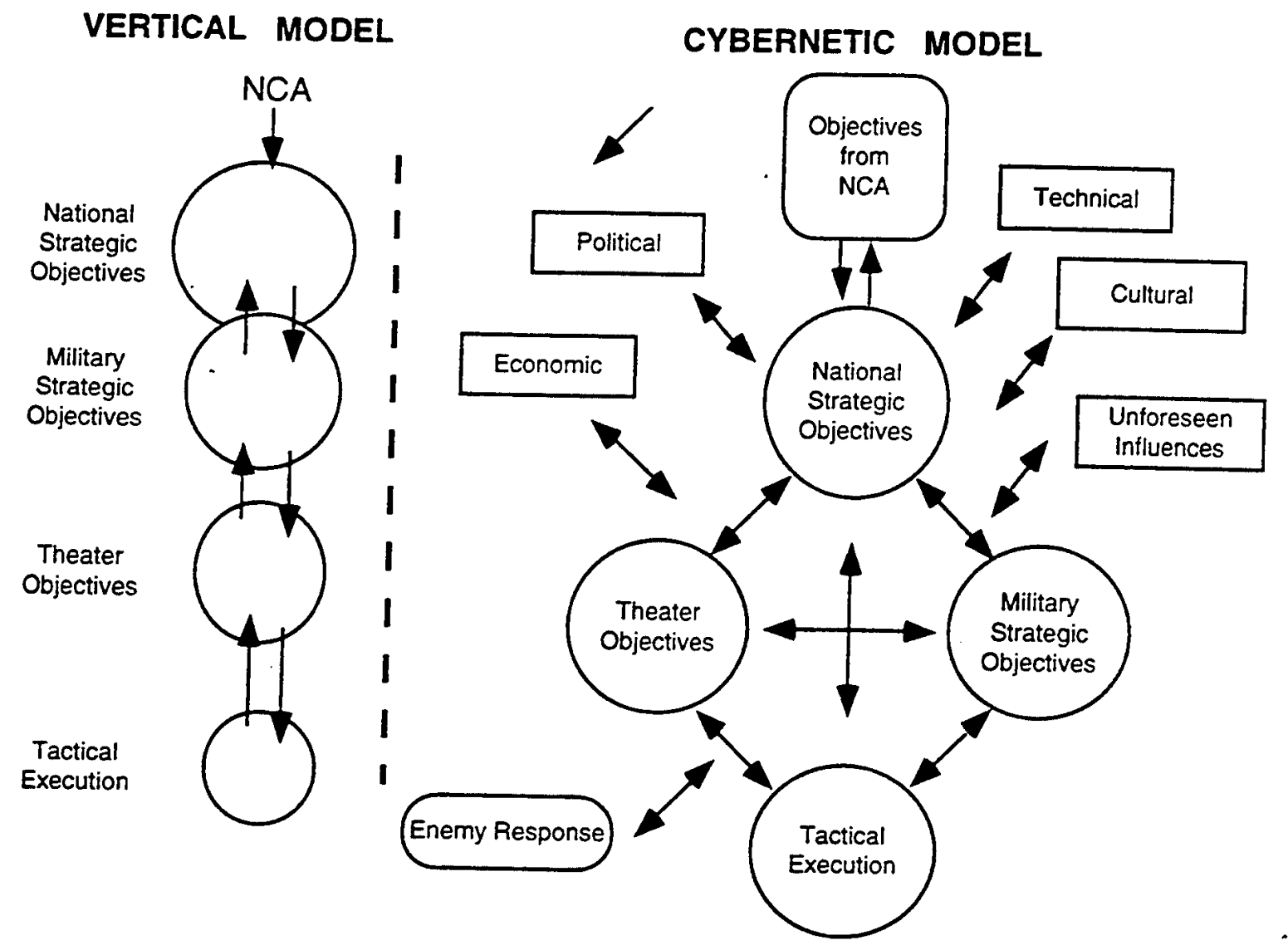

Figure 8: The military command structure as a rigid, vertical hierarchy or as a dynamic system of interacting elements (Adapted from Brungess, 1994).

A more detailed look at the information flow shows many coupled OODA Loops operating at different time constants and reflecting different levels of analysis (e.g., Whitaker \& Kuperman's 1996 analysis of Scud hunting). In his classic text on Electromagnetic Conflict, Fitts (1980) distinguishes three different analysis loops: ELINT (electronics intelligence), ESM (electronic support measures), and ECM (electronic countermeasures; Figure 9). [Note that the terms ELINT, ESM, and ECM have evolved since Fitts' (1980) characterization of the systems. The nested loops are presented here to give a sense of what the nesting of OODA loops might look like. This is not intended to be a definitive model of electromagnetic warfare.] The ELINT loop represents information that is collected over long time periods (weeks to years) and that is subject to extensive analysis and evaluation. This loop is involved in long range strategic planning. It involves a long-term analysis of allied and enemy capabilities and tendencies that helps to determine long range objectives and general strategies. 


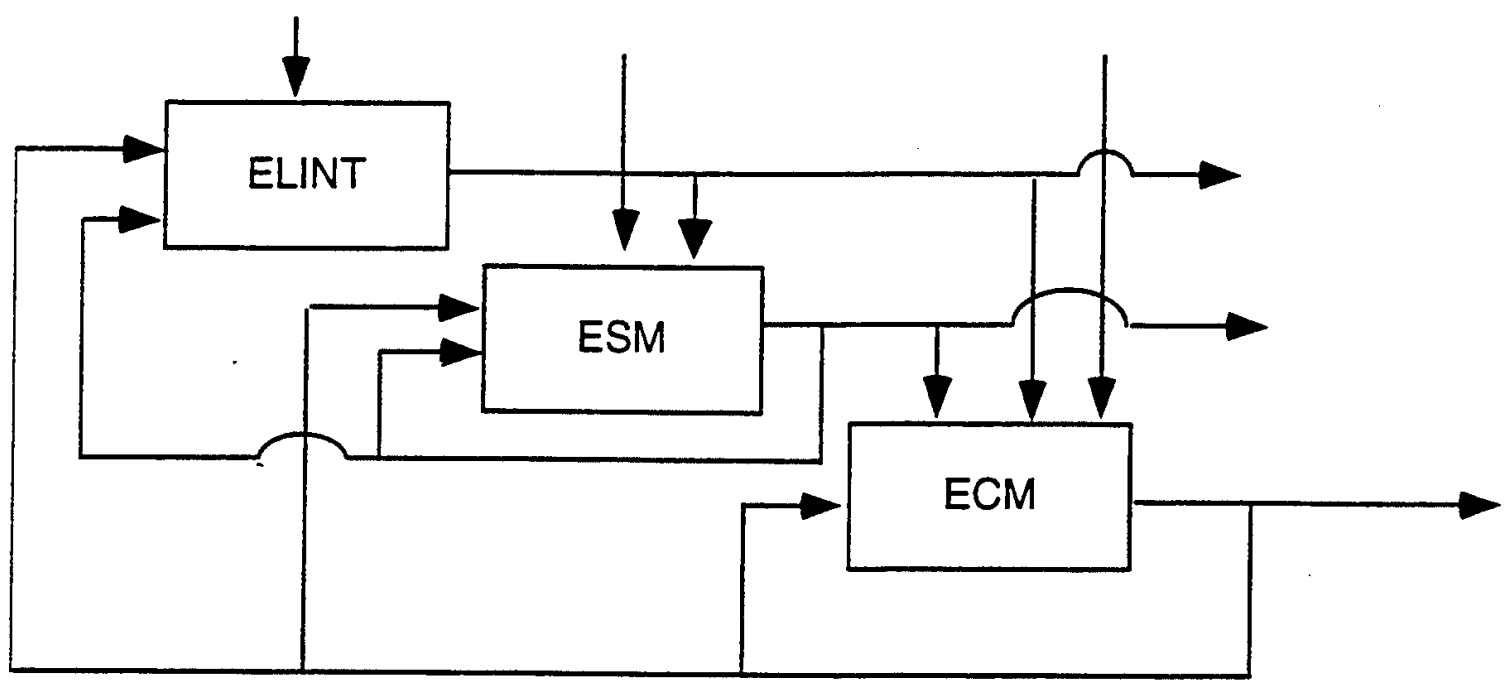

Figure 9: Electromagnetic warfare can be viewed as a nested set of control loops. The outer loops have a longer time constants.

The ESM loop operates with a smaller time constant (hours to weeks). The ESM loop reflects the information that a tactical commander would gather in order to prepare for tomorrow's mission. It might include input from regularly scheduled reconnaissance missions or from debriefs of the previous mission. The ESM loop represents tactical planning. It involves integration of highly processed data available from ELINT with raw data (with perhaps some low level analyses) obtained from recent observations of the situation. Some of the data from the current observations are also passed up to be integrated with other information as part of the ELINT loop.

Finally, there is the ECM loop. This loop has a much smaller time constant (milliseconds to hours). This loop involves the moment-to-moment actions of a pilot, a field commander, or an individual soldier in response to direct observations of the enemy. Performance within this loop reflects the plans and preparations generated in the ESM loop and the data directly available to the warfighter.

It is the couplings and time constants of these interacting loops that begins to provide a context for answering questions about the "right information" and the "right time." The general OODA Loop is far too gross a formulation for addressing these questions. A critical question is how can these loops (each operating at a different time constant and on different kinds of data) interact to build a unified Common Battlespace Picture that will support fulr consideration of options and timely decision making at all levels? 
Figure 10 (adapted from Homer, 1996) shows some of the nested loops involved in IW. Note the "push" and "pull" of information in this diagram. This emphasizes that the Common Battlespace Picture is a joint function of the available data and of the questions that analysts choose to ask. This is a critical aspect of the dynamic. All the data may be available to construct an accurate visualization of the battlespace; however, an accurate visualization may not be realized because the right questions were not asked. In CSE, the terms "data" and "information" are sometimes contrasted to make this point. Data are whatever is available from the sensors, but "information" is the answer to questions the analysts are asking. Thus, information can be missing, due either to a lack of data or to a failure to ask the right question.

An implicit assumption of the loops in Figures 6-10 is that there is a problem to be solved. The emphasis is on problem solving! However, for IW, particularly in the post cold war world era where the threats are ill-defined, the main problem may not be problem solving, but problem finding. Figure 11, adapted from Klein Associates (1997), explicitly includes problem detection within the representation of the perception-action loop. Problem finding is implicitly recognized in Figure 10 as an important aspect of "information pull." As the following quote from Klein Associates (1997) illustrates, for systems to function skillfully the analysts must be actively engaging the data (information pull):

[an] important factor is whether the problem solver forms his/her own understanding or just accepts the description provided by someone else (or by a decision support system). Having an active engagement in building up one's own interpretation is important for detecting early signs of a problem. Failures to detect problems result from lack of experience, but they also occur when people explain away early signs of the problem, and when they show an "automation bias" by passively accepting the outputs of a computer-based system. (p. 2) 


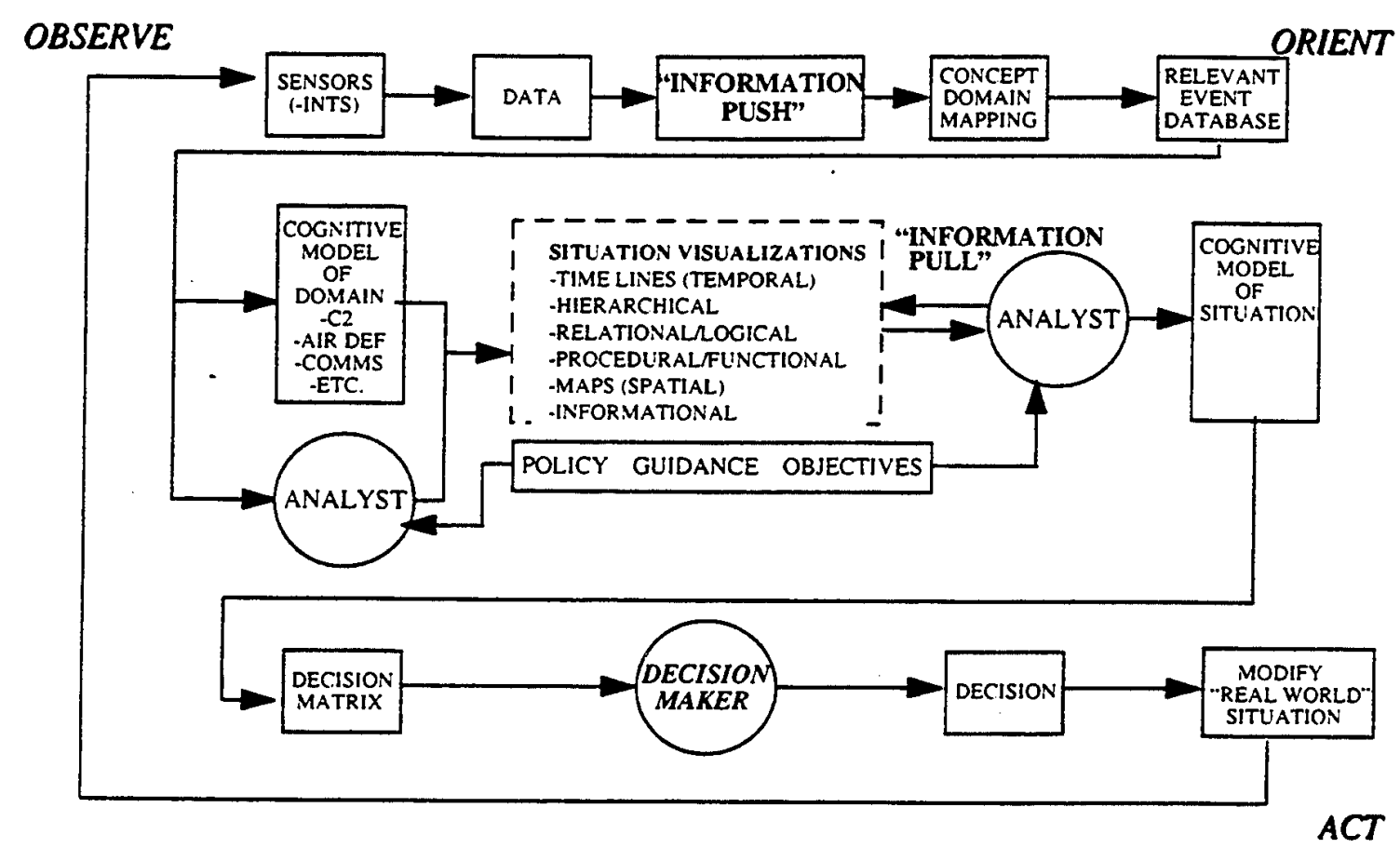

Figure 10: A hypothetical view of the general functional flow for IW (adapted from Homer, 1996).

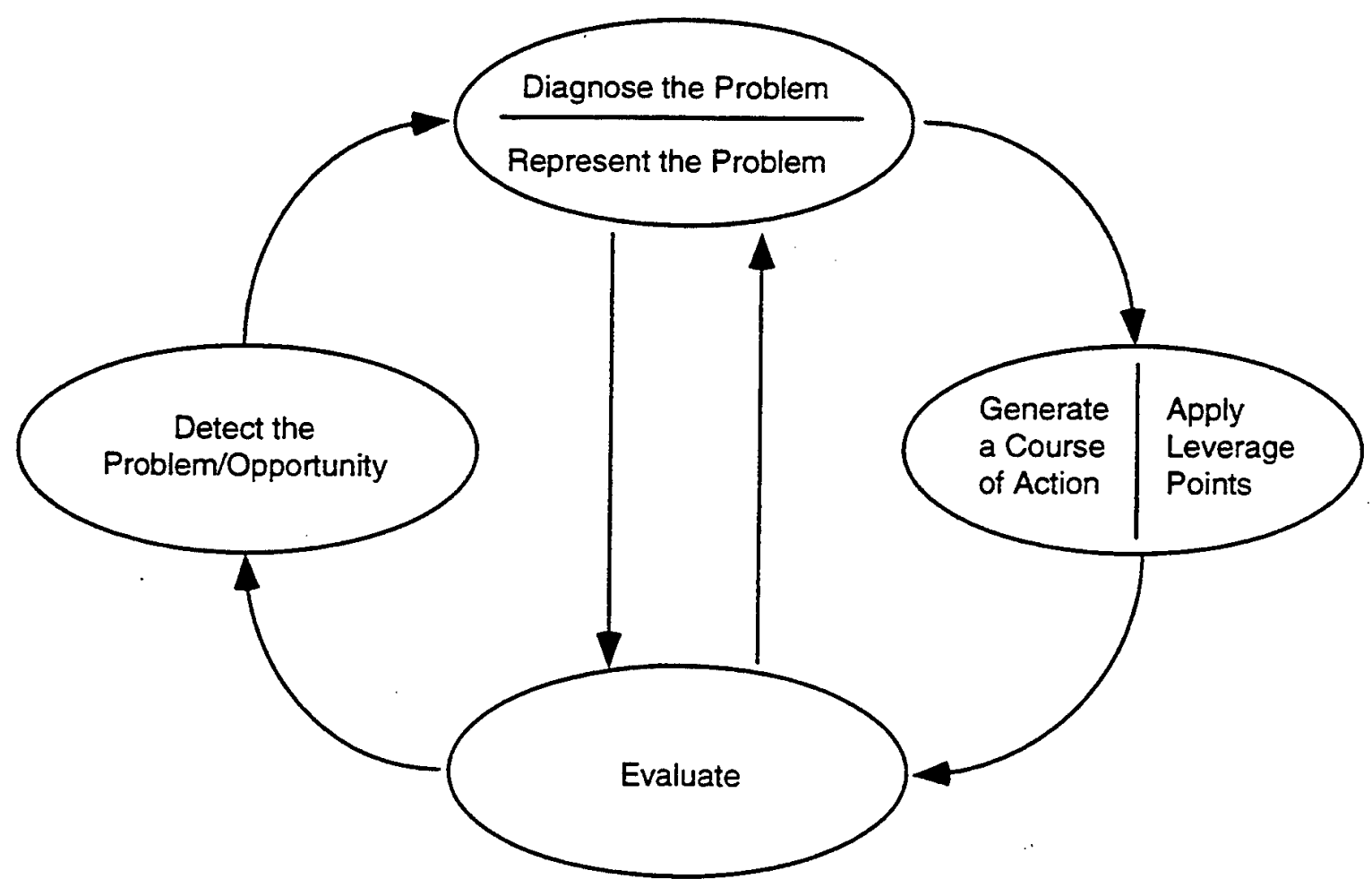

Figure 11: Explicit representation of problem finding as part of the closed-loop perception-action coupling (from Klein Associates, 1997). 


\section{Physical Function}

At this level of analysis, consideration is given to allocation of the various functions. A fundamental issue at this level concerns what tasks or functions to allocate to humans and what tasks to allocate to computers and automatic control systems. Table 2 (from Sheridan, 1996) shows some of the logical ways that machines and humans might be coupled. Certainly, IW is well beyond Level 1 of Sheridan's scale. The question is, how much beyond this level can we venture? How much can we rely on information technologies and how much authority can we give to our computational engines? Appropriate decisions about automation can enhance expertise, but inappropriate allocations may result in barriers to expertise. This will not be a simple question that can be answered once and for all. Pronouncements such as "a human will always have the final authority" are naive. The question of the degree of automation must be addressed over and over again within each of the many nested OODA loops that make up the dynamic system of IW and must be reassessed in the context of continuing advances in technology.

Table 2: Scales of degrees of automation

\begin{tabular}{|l|}
\hline \multicolumn{1}{|c|}{ Scale of Degrees of Automation (from Sheridan 1996) } \\
\hline 1. The computer offers no assistance; the human must do it all. \\
\hline 2. The computer offers a complete set of action alternatives, and \\
\hline 3. Narrows the selection down to a few, or \\
\hline 4. Suggests one, and \\
\hline 5. Executes the suggestion if the human approves, or \\
\hline 6. Allows the human a restricted time to veto before automatic execution, or \\
\hline 7. Executes automatically, then necessarily informs the human, or \\
\hline 8. Informs him or her after execution only if he or she asks, or \\
\hline 9. Informs him or her after execution if it, the computer, decides to. \\
\hline $\begin{array}{l}\text { 10. The computer decides everything and acts autonomously, ignoring the } \\
\text { human. }\end{array}$ \\
\hline
\end{tabular}

Table 3 (from Flach, Eggleston, Kuperman, \& Dominguez, 1998) outlines some important considerations with respect to the function allocation problem. The question is, which combinations of systems will result in the most efficient coordination across the various control loops? What combination of physical components will result in the greatest expertise, permit the shortest decisioncycle times and the greatest flexibility or adaptability? What allocations will minimize the barriers to expertise? 
Table 3: Key considerations for function allocation

\begin{tabular}{|l|l|}
\hline \multicolumn{1}{|c|}{ Level } & \multicolumn{1}{c|}{ Key Considerations for Function Allocation } \\
Functions & Priority. Relative importance or criticality of a particular function. Is it \\
essential or discretionary with respect to the overall mission objectives? & Precedence Constraints. Sequential dependencies across the functions. \\
To what extent do functions depend on the successful prior completion \\
of other functions? \\
Temporal Constraints. Are there fixed windows of opportunities or \\
fixed time schedules associated with particular functions? \\
Spatial Constraints. Does performance of the function depend on \\
being at a particular place or location? \\
Structural Understanding. Does the agent have the appropriate \\
knowledge or know how (e.g., right training for operators or right \\
programming for automation) to accomplish the functions? \\
Information Availability. Does the agent have adequate information \\
(good situation awareness) for completing the function? \\
Resource Availability. Does the agent have adequate information \\
processing capacity (e.g., attention, memory, computational power) or \\
physical capacity (e.g., free hand) to accomplish the function? \\
Effector Capability. Is the agent capable of performing the actions \\
necessary to complete the function? Can the agent respond in time with \\
the appropriate precision? \\
Shared Mental Models. Do the cooperating agents have a common or \\
compatible vision (e.g., common assumptions, shared rationality) of the \\
problem domain? \\
Information Coupling. Is there sufficient information for each agent to \\
know what and how other agents are doing? \\
Effector and Resource Complementarity. Do the effector and resource \\
capabilities of the team span the demands of the work domain? \\
Authority Structure. How are dynamic decisions about allocation \\
handled (e.g., central authority, first-come, consensus, volunteer, etc.)? \\
How are conflicts resolved?
\end{tabular}

A reasonable hypothesis, in the context of our understanding of expertise, is that efforts should focus on bringing the data closer to critical decision points. Two very different solutions are currently being explored. One solution is to bring the data forward, so that it is more readily available to the warfighter. The Airborne Warning and Control System (AWACS) and the Joint Surveillance Target Attack Radar System (JSTARS) are two examples where information is moved forward so that warfighters have more direct access to ELINT and ESM. Another solution is to move the decision points back to the information sources. Uninhabited combat aerial vehicles (UCAVs) are an example of this approach. That is, the warfighter's role (pilot) is automated and the decisions are moved back to a command center where ELINT and ESM data are more easily accessed and displayed. 
Which will be the best solution-moving the data forward or moving the control back? A major issue to consider, relative to moving the data forward, is the issue of cognitive workload. There is a danger that the warfighter will be overwhelmed with data. A key consideration will be the form or the representation. If representations can be designed that support recognitional processes, then more data will not necessarily mean more workload. A major concern, relative to moving control back, is that the automation of the ECM role will reduce the flexibility in that loop. Key considerations will be the time constraints on communications from the control center to the UCAV and the sophistication of the automatic control algorithms that can be implemented in the UCAV. Ultimately, this will not be a simple dichotomous choice-it will be a question of when/where/how can data be moved forward and how far forward; and when/where/how can control be moved back and how far back. Again, the issue is to get the right data to the right people at the right time!

\section{Physical Form}

At this level of analysis the specific physical form of the system and the specific trajectories of activities are considered. At the previous levels, questions were framed in terms of different aspects of the functional relations; in this section the pragmatics of actually building the physical system and of physically performing the activities are considered.

At a gross level it is clear that IW will not be bounded by the same spacetime constraints that bounded conflict in the days of Sun Tzu or even as recently as World War II. Vietnam was fundamentally different than WWII and Desert Storm was different than Vietnam. The classical partitioning of forces according to geographical distinctions of land, sea, and air will no longer be feasible. IW will require an integrated joint forces approach to war. IW is going to involve managing widely (perhaps globally) distributed forces and is going to require a degree of coordination and synchronization among those forces that has never been demanded in the past. We can also say with confidence that the human will remain a critical element in IW. Computers will be essential. The full electromagnetic spectrum will be utilized. Further, satellites and global positioning systems (GPS) will be involved. Also, it is clear that the flow of information will not be bounded by military systems. International news services and global communication systems will also be coupled more intimately to the war than ever before. Thus, the link between politics, public opinion, and military action will shape the dynamic of IW. Already, we see evidence in Desert Storm that managing mass media will be part of the IW problem.

Already, it should be apparent why this is the base of the abstraction hierarchy. The number of issues to consider at this level of analysis is staggering. These issues span many different disciplines. How is it possible to deal with all 
the potentially relevant data at this level? This is why the abstraction hierarchy is essential. The analyses at the higher levels of abstraction can be used to help parse the problem at lower levels. Thus, the categories defined at higher levels of abstraction can be used to organize and integrate data at the physical level. Having the categories does not reduce the complexity of the problem, but these categories can facilitate the management of the complexity. The categories can help to guide and bound generalizations. The categories formulated at higher levels of abstraction provide a representational framework that may facilitate expertise in making decisions about the physical form of IW systems. There are no guarantees, no simple, easy to understand recipes that will tell us what physical form IW systems should take. The hope, however, is that by working up and down the abstraction hierarchy we may be in a better position to ask the right questions and that these questions will facilitate the iterative process of generating and testing hypotheses about the physical form of the system.

\section{Summary}

Figure 12 uses the CSE Abstraction/Decomposition space to summarize the discussion in this section. As noted earlier, the diagonal within this space seems to provide the level of description that is most relevant to the design of systems that function as experts. At the top level, a general understanding of the goals provides the context for more detailed analyses at lower levels. At the bottom level, every element within the physical system must be considered in detail with regard to its interface to other pieces of the system. On one hand, a design based on a good understanding of general principles might fail because a small physical detail is overlooked (for example, an electronic suite is developed with an interface that is not compatible with other electronic systems in the cockpit). On the other hand, all the pieces can fit together well and function exactly as the designer intended, but if they were not designed in the context of the general functional requirements of the warfighter, the system may never be used. The designer solved the wrong problem.

Figure 12 is a map of where we are and the directions we need to go with respect to a CSE analysis of IW. At the Functional Purpose level there is an abundance of information about the goals and basic doctrine of warfare. For the most part, detailed analyses are not required here. It is simply a matter of communicating the information in a way that designers will appreciate.

The Abstract Function level provides a critical challenge for the analysis of IW. How do we express the functional requirements in terms that reflect measurable attributes of design solutions? Dimensions like decision-cycle time and robustness provide a first-cut, general hypothesis about dimensions that might be useful. While these dimensions might be useful for post hoc comparisons of systemic design solutions, these measures are probably too 
general to provide much guidance to designers of information technologies. Klein's (1997) discussion of the barriers to expertise associated with information technologies might provide useful hints that might provide the basis for a higher-dimensional description of the design space. On the other hand, classical engineering measures of probability of kill or probability of survival are probably too elemental -in that their measurement will typically require restrictive assumptions about the operational context.

The General Function level also is a challenge. It is clear that IW will involve a closed-loop perception-action dynamic as typified by the OODA Loop. However, it will be a complex network of interconnected loops operating with different time constants and operating at different levels of data decomposition and integration. In order to fully characterize this network it will be necessary to develop detailed models of prototypical IW systems (e.g., Whitaker and Kuperman's (1996) analysis of Scud hunting) and then, through comparisons and contrasts among these systems, it may be possible to abstract a picture of the general functions that govern the flow of information and action for IW. The functional flow representation must make both the "push" and "pull" (e.g., problem finding) aspects of IW explicit.

The Physical Function and Physical Form levels represent the pragmatics of the design problem. At this point, analyses should begin with evaluations of general solutions (across different domains, as typified by Sheridan's list) and particular solutions that exist for IW (e.g., JSTARS and UAVs). What works? Where are there difficulties? These kinds of observations will be useful for understanding how the different functional components (humans and machines) can most effectively be coupled and will draw attention to key elements of physical form that may be critical to performance.

It is important to appreciate the fact that the diagonal of the CSE space is a target that can only be approached asymptotically. That is, there will always be unanswered questions. Our understanding will never be complete. Partly, this is due to the fact that technologies are not stationary - they are continuously evolving. But, more fundamentally, it is due to the nature of the design and discovery process. The CSE analysis cannot be isolated as a precursor to design. The CSE analysis must be integrated within the iterative process of design. The CSE analysis is a mechanism for generating hypotheses. Each design is a test of our hypotheses. The results from each test must be fed back into the analysis process so that we can generate better hypotheses. In an important sense, CSE is not an external framework for evaluating IW. Rather, CSE is intrinsic to IW. CSE is the basis for a proactive (as opposed to reactive) approach to IW. CSE is an integral framework for planning the future of IW. 


\begin{tabular}{|c|c|c|c|c|c|}
\hline \multicolumn{6}{|c|}{ AGGREGATION - DECOMPOSITION } \\
\hline & General & & & & Elemental \\
\hline $\begin{array}{l}\text { FUNCTIONAL } \\
\text { PURPOSE }\end{array}$ & $\begin{array}{c}\text { Doctrine: } \\
\text { Principles } \\
\text { of } \\
\text { War }\end{array}$ & & & $\cdot$ & \\
\hline $\begin{array}{l}\text { ABSTRACT } \\
\text { FUNCTION }\end{array}$ & $\begin{array}{c}\text { Expertise: } \\
\text { Decision } \\
\text { Speed } \\
\text { Robustness }\end{array}$ & $\begin{array}{c}\text { More Refined } \\
\text { Measures } \\
\text { of Expertise }\end{array}$ & & $\begin{array}{c}\% \text { kills } \\
\% \text { survived }\end{array}$ & \\
\hline $\begin{array}{l}\text { GENERAL } \\
\text { FUNCTION }\end{array}$ & $\begin{array}{l}\text { OODA } \\
\text { Loop }\end{array}$ & $\begin{array}{l}\text { Nested } \\
\text { ELINT, ESM } \\
\text { ECM Loops }\end{array}$ & $? ? ?$ & & \\
\hline $\begin{array}{l}\text { PHYSICAL } \\
\text { FUNCTION }\end{array}$ & $\begin{array}{l}\text { Sheridan's } \\
\text { Levels of } \\
\text { Automation }\end{array}$ & & & $? ? ?$ & $\begin{array}{c}\text { AWACS } \\
\text { JSTARS } \\
\text { UAVS }\end{array}$ \\
\hline $\begin{array}{c}\text { PHYSICAL } \\
\text { FORM }\end{array}$ & $\begin{array}{l}\text { JOINT } \\
\text { FORCES }\end{array}$ & $\begin{array}{c}\text { Highly } \\
\text { Distributed } \\
\text { Network }\end{array}$ & $\begin{array}{c}\text { Humans } \\
\text { Computers } \\
\text { Satellites } \\
\text { Electromagnetic } \\
\text { Spectrum }\end{array}$ & & ??? \\
\hline
\end{tabular}

Figure 12: Fleshing out the CSE framework with some observations about IW. 


\section{FUTURE DIRECTIONS.}

In the previous section we attempted to present an overview showing where we are and the directions in which we ought to be moving in order to design for IW in the future. In this final section, we will present some suggestions for how to proceed.

\section{Hypothesis Testing vs. Hypothesis Generation}

Our society places great faith in the scientific method-and for many the scientific method is synonymous with empirical experiments. Therefore, there is a common expectation that the first step to understanding IW will be to do some experiments. The first impulse is to generate data! So, if there are questions about a particular technology, then let's do an experiment in which we compare performance of the new technology with a control condition using the old technology. We test two groups in an identical battle scenario. If the group who has the new technology has a greater percentage of hits and/or has fewer losses, then we can infer that the new technology is beneficial. Obviously, this is a clear, straightforward, wrong approach to the problem.

The first problem with this approach is the attribution problem. Was the difference (or lack of difference) in performance due to differences in the technology? Anyone familiar with experimental design realizes that there are many potential confounds (e.g., individual differences) that must be dealt with. There are ways to reduce the confounding, but even in the simplest experiments the potential for confounding cannot be totally eliminated. However, for complex systems and new technologies the attribution problem is further complicated by the fact that there is never a simple dichotomy (e.g., old technology vs. new technology). For example, you can't do a single experiment to compare graphical displays to numeric displays of information. There are an infinite number of ways that a graphical display might be implemented in a design. So, it would be a mistake to throw out graphical display technology, because one particular implementation of a graphical display did not work. The idea of a "critical experiment" is probably a fiction that we have created in our narrative retelling of the story of science. It is definitely a fiction with regard to the problem of evaluating complex technologies for application in complex work domains. To quote Alan Newell (1973)_- You can't play 20 questions with nature and win!"

A second problem with the hypothesis testing approach is the generalization problem. Is the scenario that you choose for your test representative of the actual operational environment or of the future environments where the system will eventually be implemented? Are the 
subjects in your experiment representative of the ultimate user population? If the experimental context is not representative of the operational context, then the differences observed in the experiment may be totally irrelevant to the design questions that originally motivated them. You may have exactly the right representation for the "toy" world employed in the laboratory, but it may be exactly the wrong representation for the operational problem.

A third problem with the hypothesis testing approach is the measurement problem. Are the performance measures that you collect in the experiment sensitive to the differences that make a difference in the operational environment? As Brungess (1996) notes "SEAD effectiveness in Vietnam was measured generally by counting destroyed SAM sites and radars. Applying that criteria to the SEAD technologies used in Desert Storm yields a confused, possibly irrelevant picture" (pp. 51-52).

The point to be made here is that a hypothesis testing program of research may generate lots of data, but it does not allow you to avoid the problems posed by the Abstraction Hierarchy. Without the kind of conceptual framework provided by the Abstraction Hierarchy, the data from a "twenty questions approach" will not yield information relevant to the design questions. Hypothesis testing is a reactive mode of science. It will generally lag well behind the design questions and will never keep up with the evolution of new technologies. For example, the graphical desktop interface on personal computers was not discovered by Human Computer Interface (HCI) researchers. It was a product of the design process. Laboratory-based research in $\mathrm{HCI}$ is still struggling to explain why this interface works as well as it does.

The problems of design require a proactive approach to science. The emphasis needs to be on exploration of the phenomenon, discovery, and hypothesis generation. The first step in this program of research is for researchers to immerse themselves in specific phenomena. The model for this kind of science is anthropology or ethology (not experimental physics). The challenge is to enter a work environment and to discover the intrinsic semantics of that environment. The challenge in doing this is to release our natural biases and expectations about what is logical so that we can discover the natural intrinsic logic (eco-logic) of the work domain. Again, remember the examples from Rasmussen and Klein-expectations based on normative logics are generally not validated when tested against performance of experts in their natural domain.

\section{First Step}

The first step in this program should be to identify some specific examples where new technologies are being implemented in ways that might be 
representative of the general problems of IW (e.g., Scud hunting, AWACS, UCAVs). These specific applications then need to be placed under a microscope. That is, the specific examples need to be studied intensively using table-top analysis methods, naturalistic observation, and knowledge elicitation techniques (see Flach, Eggleston, Kuperman, \& Dominguez, 1998 for descriptions of these methods in the context of UCAVs; see also Carnegie Group, 1997 for a review of knowledge elicitation tools; or Klein, 1997 for a discussion of naturalistic observations of teams).

The data acquired from these explorations must then be integrated using the CSE framework. The goal is to build a CSE description of each specific example. In other words, the preliminary goal is to fill in as much of the diagonal of the Abstraction/Decomposition space as possible. This will be an iterative process of observing, analyzing, and refining observations. Analyses must proceed simultaneously at all five levels of abstraction. Further, it must proceed in such a way that discoveries at each level inform (and are tested against) discoveries at other levels. The initial tests of these observations will be the ability to predict events in the natural environment and the internal consistency across levels of abstraction.

As an internally consistent description emerges, then we may be in a position to formulate reasonable experimental tests of some of our hypotheses. The most important tests of our hypotheses, however, will not necessarily be laboratory experiments, but rather they will be designs (Kirlik, 1995). The ultimate test of the CSE analysis is whether the data can be integrated, not as an abstract data base, but as concrete solutions. The CSE paradigm must ultimately be tested against the problem of design. To be more precise, the value of CSE will be measured against our ability to engineer effective problem representations. These representations will be implemented either as interfaces (external representations) or as training protocols (internal representations).

The term interface is used here in its broadest sense. This includes all of the technologies that stand between the human operators and the problem space with which they are interacting. For example, it includes displays and controls (in all modalities) and any computational engines (e.g., decision aids, filters, simulations, etc.) that might be used in the analysis and decision making process.

The term "training" includes classical forms of instruction. However, there is clear evidence that traditional classroom or textbook approaches to instruction are not sufficient to developing expertise. The development of the recognitional or perceptual skills of expertise requires practice, practice, practice! Thus, an important part of the CSE design effort will focus on incorporating the developing understanding of the problem into high fidelity simulations where operators can "exercise" their skills in conditions that are as close to "real game" 
conditions as possible. A bonus of this process is that the high-fidelity training simulations also offer a test-bed for empirically evaluating interfaces (and, conversely, high-fidelity concept demonstration facilities, if developed early in an evolutionary design process, may be migrated into the training support system world of application). These high-fidelity simulations offer a middle ground between the "toy worlds" of the bench scientists and the operational world of the field researcher. Thus, they offer the possibility for research programs that can have both high internal validity (control over potential confounds, precise manipulation of independent variables, and precise measurement) and high external validity (the context is representative of the natural ecology). 


\section{CONCLUSIONS}

War is a complex and chaotic human endeavor. Human frailty and irrationality shape war's nature. Uncertainty and unpredictability-what many call the "fog" of war-combine with danger, physical stress, and human frailty to produce "friction," a phenomenon that makes apparently simple operations unexpectedly, and sometimes insurmountably, difficult. Uncertainty, unpredictability, and unreliability are always present, but sound doctrine, leadership, organization, core personal values, technologies, and training can lessen their effects. (Air Force 1-1, 1997)

Will advances in information technologies provide new tools for managing the fog and friction of war, or will they further complicate the problem - exaggerating uncertainty and reducing reliability? Certainly, support for both sides of this question is available. There are many examples where advances in computational power and in graphical displays have facilitated problem solving and led to increased efficiency and reliability. On the other hand, one does not have to look far to find examples of "clumsy automation," where technology is a barrier to expertise.

The path to "clumsy automation" is a seductive one, and there is some evidence that we may already be heading down that path (e.g., Owens, 1995). It is important that we heed this warning from Rochlin (1993):

the attitudes of many of those responsible for the design and implementation of the new systems have decidedly Taylorist resonances-right down to the scientific belief that there is indeed 'one best way' to perform any task, including a managerial one. Even more striking is the return to the search for central control (Beninger, 1986). In her interviewing, Zuboff (1984) noted several instances where the manager's view of the intended result was a centralization of control in order to reduce uncertainty and allow syncretic planning of all operations. As she reported, a survey of plant managers conducted by the Honeywell Corporation found that "almost without exception, the "technology ideal" reported by plant managers was having one screen in their office from which they could operate the entire plant" (p. 283). In another cited study, Robert Howard finds that information systems "are indeed being used to reproduce the logic of scientific management-top down control, centralization of knowledge, de-skilling-more comprehensively than ever before. (Howard, 1985 p. 207)

A skilled warrior must be fast (efficient) and adaptable (robust). It is easy to see how technologies can be utilized to increase speed and efficiency in data handling-but it is less clear whether this increase in data availability 
translates into a smarter warrior. A danger of automation is that the warrior will become an automaton (see Figure 5). Thus, the system will be fast, but brittle.

The increased efficiency will be at the expense of robustness. This is the fundamental design challenge-to harness the efficiency that information technologies offer without sacrificing the adaptability that the experienced human can contribute. The objective is to integrate the humans and technologies into a system that functions more efficiently and reliably than either would function alone. The technology should complement and amplify the human's natural capacities for expertise.

One of the most exciting aspects of the relation between CSE and IW are the many analogs between the problem space of the IW analyst and of the CSE designer. Both the IW and the CSE communities are faced with "messy" or "illdefined" problems. To illustrate that, we have paraphrased the characterization of war used to open this section in terms of design:

Design is a complex and chaotic human endeavor. Human frailty and irrationality shape design's nature. Uncertainty and unpredictability-what many call the "fog" of design-combine with economic risks, political pressures, and human frailty to produce "friction," a phenomenon that makes apparently simple problems unexpectedly, and sometimes insurmountably, difficult. Uncertainty, unpredictability, and unreliability are always present, but sound doctrine, leadership, organization, core personal values, technologies, and training can lessen their effects.

In some respects, IW is not about a type of war that will be fought in the future against a to-be-named enemy. IW is a battle that is raging at this instant. It is a war between humans and technology. It is a struggle to see whose "will" will dominate. Will advances in information technology be instruments for furthering human intentions, or will humans be overwhelmed by the complexity and become hostages to those technologies? In this respect, CSE is an offensive (proactive) strategy for fighting this war. As Section II illustrates, this strategy is a natural evolution that stems from struggles with earlier technologies. Section III presents a general framework for building a Common Battlespace Picture for planning this war. Section IV begins to flesh out this Common Battlespace Picture relative to a preliminary reconnaissance of the battlespace. Section $V$ suggests some general tactics and some specific first steps for engaging the enemy.

The goal is to impose our will on complex technologies. We would like to develop a unified approach that is simple, economical, and has clearly defined objectives. We would like to be proactive in attacking this battlespace-we want to dictate the pace of the engagement and we want to mass our resources where they will have the greatest positive effect with the minimum risks. In many 
respects, technology is the barbarian at our gate and CSE represents our best strategy for preparing for victory by design. Victory over our information technologies may be the most effective path to peace in our world.

To be prepared for war is one of the most effectual means of preserving peace.

George Washington 


\section{TERMS \& ACRONYMS}

AWACS

BHEP

$\mathrm{CSCW}$

CSE

DoD

ECM

ELINT

ESM

GDSS

GPS

JSTARS

IADS

IW

JSEAD

OODA

PSF

RMA

RPD

SAM

SEAD

Scud

THERP

UAV

UCAV

VR
Airborne Warning and Control System

Basic Human Error Probability

Computer Supported Cooperative Work

Cognitive Systems Engineering

Department of Defense

Electronic Countermeasures

Electronics Intelligence

Electronic Support Measures

Group Decision Support Systems

Global Positioning System

Joint Surveillance and Target Attack Radar System Integrated Air Defense System

Information Warfare

Joint Suppression of Enemy Air Defenses

Observe, Orient, Decide, Act

Performance Shaping Factors

Revolution in Military Affairs

Recognition-Primed Decisions

Surface-to-Air Missile

Suppression of Enemy Air Defenses

Surface-to-Surface Missile System

Technique for Human Error Rate Prediction

Uninhabited Aerial Vehicle

Uninhabited Combat Air Vehicle

Virtual Reality 


\section{REFERENCES}

Bannon, L.J. (1989). Shared information spaces: .Cooperative user support networks. In Proceedings of the Conference on Mutual Uses of Science and Cybernetics (pp. 12-20). Amsterdam: University of Amsterdam.

Beniger, J.R. (1986). The control revolution: Technological and economic origins of the information society. Cambridge, MA: Harvard University Press.

Bennett, K.B. \& Flach, J.M. (1992). Graphical displays: Implications for divided attention, focused attention, and problem solving. Human Factors, 34(5), 513-533.

Bennett, K.B., Nagy, A. \& Flach, J.M. (1997). Visual displays. In G. Salvendy (Ed.), Handbook of human factors (pp. 659-696). Mahwah, NJ: Erlbaum.

Boyd, J.R. (1987). A discourse on winning and losing (Report No. MU43947). Air University Library, Maxwell AFB, AL. An unpublished briefing.

Brungess, J.R. (1994). Setting the context: Suppression of enemy air defenses and joint war fighting in an uncertain world. Maxwell AFB, AL: Air University Press.

Carnegie Group (June 26 1997). Intelligent cognitive engineering suite for information warfare domains. (Interim Report). Wright-Patterson AFB: Armstrong Laboratory, Human Engineering Division.

Christensen, J. (1947). Psychological factors involved in the design of air navigation plotters. In P.M. Fitts (Ed.), Psychological research on equipment design (Report No. 19; pp. 73-90). Washington, DC: U.S. Government Printing Office.

Christensen, J. (1949). A method for the analysis of complex activities and its application to the job of the Arctic aerial navigator. Mechanical Engineering, 71.

Department of the Air Force (1997). Air Force Manual 1-1, Basic Aerospace Doctrine of the United States Air Force. Washington, DC: Department of the Air Force.

Department of the Air Force (October 1996). Air Force Doctrine Document 5 (AFDD 5), Information Warfare (Second Draft). Washington, DC: Department of the Air Force

Dominguez, C. (1997). First do no harm: Expertise and metacognition in laparoscopic surgery. Unpublished dissertation. Wright State University, Dayton, $\mathrm{OH}$.

Edwards, E. (1988). Introductory overview. In E.L. Wiener \& D.C. Nagel (Eds.), Human factors in aviation (pp. 3-25). New York: Academic Press.

Fitts, P.M. \& Jones, R.E. (1947a). Psychological aspects of instrument display. I. Analysis of 270 "pilot-error" experiences in reading and interpreting instruments 
(USAF Air Materiel Command Mem. Report TSEAA-694-12A). WrightPatterson AFB, OH: Air Materiel Command.

Fitts, P.M. \& Jones, R.E. (1947b). Analysis of factors contributing to 460 "pilot-error" experiences in operating aircraft controls (USAF Air Materiel Command Mem. Report TSEAA-694-12). Wright-Patterson AFB, OH: Air Materiel Command.

Fitts, R.E. (1980). The strategy of electromagnetic conflict. Los Altos, CA: Peninsula Publishing.

Flach, J.M. (1995). Situation awareness: Proceed with caution. Human Factors, $37(1), 149-157$.

Flach, J.M. (1997). Flight and ground vehicle simulation: A tool for skill development. Lecture presented in the Flight and Ground Vehicle Simulation Course. Binghamton, NY: Watson School of Continuing Education, Binghamton State University of New York.

Flach, J.M. \& Bennett, K.B. (1996). A theoretical framework for representational design. In R. Parasuraman \& M. Mouloua (Eds.), Automation and human performance: Theory and applications (pp. 65-87). Mahwah, NJ: Erlbaum.

Flach, J.M., Eggleston, R., Kuperman, G., \& Dominguez, C. (1998). SEAD and the UCAV: A preliminary cognitive systems analysis (Report No. AFRL-HE-WPTR-1998-0013). Wright-Patterson AFB, OH: Air Force Research Laboratory, Crew System Interface Division.

Flach, J.M., Hancock, P.A., Caird, J.K., \& Vicente, K.J. (1995). Global perspectives on the ecology of human-machine systems. Mahwah, NJ: Erlbaum.

Flach, J.M., Lintern, G., \& Larish, J.F. (1990). Perceptual motor skill: A theoretical framework. In R. Warren \& A. Wertheim (Eds.), Perception \& control of self-motion (pp. 327-355). Hillsdale, NJ: Erlbaum.

Flach, J.M., Lintern, G., \& Larish, J.F. (1990). Perceptual motor skill: A theoretical framework. In R. Warren \& A. Wertheim, (Eds.), Perception and control of self-motion (pp. 327-355). Mahwah, NJ: Erlbaum.

Flach, J.M. \& Rasmussen, J. (in press). Cognitive engineering: Designing for situation awareness. In N. Sarter \& R. Amalberti (Eds.), Cognitive Engineering in the Aviation Domain. Mahwah, NJ: Erlbaum.

Gleik, J. (1987). Chaos: Making a new science. New York: Viking Penguin.

Grether, W.F. (1949). Psychological factors in instrument reading. I. The design of long-scale indicators for speed and accuracy of quantitative readings. Journal of Applied Psychology, 33(4), 363-372.

Hammond, K.R. (1993). Naturalistic decision making from a Brunswikian viewpoint: Its past, present, and future. In G.A. Klein, J. Orasanu, R. 
Calderwood, \& C. Zsambok (Eds.), Decision making in action: Models and methods (pp. 205-227). Norwood, Ablex.

Hancock, P.A. (1996). Teleology for technology. In R. Parasuraman \& M. Mouloua (Eds.), Automation and human performance (pp. 461-497). Mahwah, NJ: Erlbaum.

Hayek, F.A. (1988). The fatal conceit: The errors of socialism. In W.W. Bartley III (Ed.), The collected works of F.A. Hayek, Vol. 1. Chicago: University of Chicago. Press.

Homer, J. (12 July 1996). Jumpstart Initiative and Decision Support System Development Plan. Briefing to Air Force Materiel Command. (AFMC/ST).

Howard, R. (1985). Brave new workplace. New York: Viking.

Hutchins, E. (1995). Cognition in the wild. Cambridge, MA: MIT Press.

Jenkins, W.O. (1947). The tactual discrimination of shapes for coding aircrafttype controls. In P.M. Fitts (Ed.), Psychological research on equipment design. (Report No. 19; pp. 199-205). Washington, DC: U.S. Government Printing Office.

Kirlik, A. (1995). Requirements for psychological models to support design: Toward ecological task analysis. In J.M. Flach, P.A. Hancock, J.K. Caird, \& K.J. Vicente (Eds.), Global perspectives on the ecology of human-machine systems (pp. 68-120). Mahwah, NJ: Erlbaum.

Klein, G. (1993). A recognition-primed decision (RPD) model of rapid decision making. In G.A. Klein, J. Orasanu, R. Calderwood, \& C. Zsambok (Eds.), Decision making in action: Models and methods (pp. 205-227). Norwood, NJ: Ablex.

Klein, G. (1997). Implications of the naturalistic decision making framework for information dominance (Report No. AL/CF-TR-1997-0155). Wright-Patterson AFB, OH: Armstrong Laboratory, Human Engineering Division.

Klein, G., Calderwood, R., \& Clinton-Cirocco, A. (1986). Rapid decision making on the fireground. Proceedings of the $30^{\text {th }}$ Annual Meeting of the Human Factors Society, 576-580.

Klein, G., Orasanu, J., Calderwood, R., \& Zsambok, C. (1993). Decision making in action: Models and methods. Norwood, NJ: Ablex.

Konz, S. (1987). Work design: Industrial ergonomics. Columbus, OH: Publishing Horizons, Inc.

Marr, D. (1980). Vision. New York: Freeman.

Neisser, U. (1976). Cognition and reality: Principles and implications of cognitive psychology. San Francisco: W.H. Freeman. 
Newell, A. (1973). You can't play 20 questions with nature and win. In W.G. Chase (Ed.), Visual information processing (pp. 283-308). New York: Academic Press.

Owens, W.A. (1995). Introduction In S. E. Johnson \& M.C. Libicki (Eds.), Dominant battle space knowledge: The winning edge (pp. 3-18). Washington, DC: National Defense University Press.

Perrow, C. (1984). Normal Accidents: Living with high-risk technologies. New York: Basic Books.

Rasmussen, J. (1986). Information processing and human-machine interaction: An approach to cognitive engineering. New York: North Holland.

Rasmussen, J. \& Jensen, A. (1973). A study of mental procedures in electronic troubleshooting (Report No. M-1582). Roskilde, Denmark: RISØ National Laboratory.

Rasmussen, J., Pejtersen, A.M. \& Goodstein, L. (1994). Cognitive Systems Engineering.

Rasmussen, J. \& Vicente, K.J. (1989). Coping with human errors though system design: Implications for ecological interface design. International Journal of Man-Machine Studies, 31, 517-534.

Rochlin, G. (1989). Informal organizational networking as a crisis avoidance strategy: U.S. Naval Flight Operations as a case study. Industrial Crisis Quarterly, 3, 159-176.

Rochlin, G. (1993). Essential friction: Error-control in organizational behavior. In N. Akerman (Ed.), The necessity of friction: Nineteen essays on a vital force (pp. 196-234). Heidelberg: Physica-Verlag.

Rochlin, G., LaPorte, T. R., \& Roberts, K. (Autumn 1987). The self-designing high-reliability organization: Aircraft carrier flight operations at sea. Naval War College Review, 40(4), 76-90.

Sanderson, P.M., Flach, J.M., Buttigieg, M.A., \& Casey, E.J. (1989). Object displays do not always support better integrated task performance. Human Factors, 31(2), 183-198.

Sheridan, T.B. (1996). Speculations on future relations between humans and automation. In R. Parasuraman \& M. Mouloua (Eds.), Automation and human performance (p. 449-460). Mahwah, NJ: Erlbaum.

Sun Tzu (1966). The art of war. Adapted by S. Rudnicki. West Hollywood, CA: Dove Books.

U.S. Department of Defense (1988). Investigation report: Formal investigation into the circumstances surrounding the downing of Iran Air Flight 655 on 3 July 1988. Washington, DC: U.S. Department of Defense. 
Vicente, K.J. (1992). Memory recall in a process control system: A measure of expertise and display effectiveness. Memory and Cognition 20, 356-373

Vicente, K.J. (1997). Should an interface always match an operator's mental model? CSERIAC Gateway, VIII(1), 1-5.

Vicente, K.J. \& Wang, J. (1998). An ecological theory of expertise effects in memory recall. Psychological Review, 105, 33-57.

Waldrop, M.M. (1992). Complexity: The emerging science at the edge of order and change. New York: Simon \& Schuster.

Watts, B.D. (1996). Clausewitzian friction and future war (McNair Paper No. 52). Ft. Leslie J. McNair, DC: National Defense University, Institute for National Strategic Studies.

Whitaker, R.D. \& Kuperman, G.G. (1996). Cognitive engineering for information dominance: A human factors perspective (Report No. AL/CF-TR-1996-0159). Wright-Patterson AFB, OH: Armstrong Laboratory, Human Engineering Division.

Widnall, S.E. \& Fogleman, R.R. (1995). Cornerstones of information warfare. Washington, DC: Department of the Air Force.

Woods, D.D. (1991). The cognitive engineering of problem representations. In G.R.S. Weir \& J.L. Alty (Eds.), Human computer interaction and complex systems (pp. 169-188). London: Academic Press.

Zubov, S. (1984). In the age of the smart machine. New York: Basic Books. 